\title{
Cannabinoid receptor interacting protein Crip1a modulates CB1 receptor signaling in mouse hippocampus
}

Stephan Guggenhuber ${ }^{1}$, Alan Alpar ${ }^{2,3,4}$, Rongqing Chen ${ }^{5}$, Nina Schmitz ${ }^{1}$, Melanie Wickert $^{1}$, Tobias Mattheus ${ }^{1}$, Anne E. Harasta ${ }^{1,6}$, Martin Purrio ${ }^{1}$, Nadine Kaiser ${ }^{1}$, Maurice R. Elphick ${ }^{7}$, Krisztina Monory ${ }^{1}$, Werner Kilb ${ }^{5}$, Heiko J. Luhmann ${ }^{5}$, Tibor Harkany $^{2,8}$, Beat Lutz ${ }^{1, *}$, Matthias Klugmann ${ }^{1,6, *}$

${ }^{1}$ Institute of Physiological Chemistry, University Medical Center of the Johannes Gutenberg University, D-55128 Mainz, Germany. ${ }^{2}$ Division of Molecular Neurobiology, Department of Medical Biochemistry and Biophysics, Scheeles väg 1:A1, Karolinska Institutet, SE-17177 Stockholm, Sweden. ${ }^{3}$ Research Group of Experimental Neuroanatomy and Developmental Biology, Hungarian Academy of Sciences, Budapest, Hungary. ${ }^{4}$ Department of Anatomy, Histology and Embryology, Semmelweis University, Budapest, Hungary. ${ }^{5}$ Institute of Physiology, University Medical Center of the Johannes Gutenberg University, D-55128 Mainz, Germany. ${ }^{6}$ Department of Physiology \& Translational Neuroscience Facility, School of Medical Sciences, UNSW, High Street, Randwick, NSW 2052, Sydney, Australia. ${ }^{7}$ School of Biological \& Chemical Sciences, Queen Mary University of London, London E1 4NS, UK. ${ }^{8}$ Department of Molecular Neuroscience, Center for Brain Research, Medical University of Vienna, Spitalgasse 4, A-1090 Vienna, Austria.

Short title: CRIP1a modulates CB1 receptor in vivo

"Correspondence should be addressed to Matthias Klugmann or Beat Lutz. E-mail: m.klugmann@unsw.edu.au or blutz@uni-mainz.de.

Key words: CRIP1a, hippocampus, cannabinoid receptor, seizures, AAV 


\section{Abstract}

The cannabinoid type 1 receptor (Cnr1, CB1R) mediates a plethora of physiological functions in the central nervous system (CNS) as a presynaptic modulator of neurotransmitter release. The recently identified cannabinoid receptor interacting protein 1a (Cnrip1a, CRIP1a) binds to the C-terminal domain of CB1R, a region known to be important for receptor desensitization and internalization. Evidence that CRIP1a and CB1R interact in vivo has been reported, but the neuroanatomical distribution of CRIP1a is unknown. Moreover, while alterations of hippocampal CRIP1a levels following limbic seizures indicate a role in controlling excessive neuronal activity, the physiological function of CRIP1a in vivo has not been investigated. In this study, we analyzed the spatial distribution of CRIP1a in the hippocampus and examined CRIP1a as a potential modulator of CB1R signaling and trafficking. We found that Cnrip1a mRNA is co-expressed with Cnr1 mRNA in pyramidal neurons and interneurons of the hippocampal formation. CRIP1a protein profiles were largely segregated from CB1R profiles in mossy cell terminals but not in hippocampal CA1 region. CB1R activation induced relocalization to close proximity with CRIP1a, which coincided with alleviated CB1R internalization. AAV-mediated overexpression of CRIP1a specifically in the hippocampus revealed that CRIP1a modulates CB1R activity by enhancing cannabinoid-induced $G$ protein activation. CRIP1a overexpression extended the depression of excitatory currents by cannabinoids in pyramidal neurons of the hippocampus and diminished the severity of chemically induced acute epileptiform seizures. Collectively, our data indicate that CRIP1a enhances CB1R signaling in vivo. 


\section{Introduction}

The cannabinoid type 1 receptor (CB1R) is the most abundant G-protein-coupled receptor (GPCR) in the mammalian central nervous system (Mechoulam and Parker 2013). CB1R signaling exerts important physiological functions, including retrograde inhibition of neurotransmitter release, control of neuronal excitability and regulation of various forms of long-term synaptic plasticity (Katona and Freund 2012). CB1R has been shown to be a promising target for the therapy of neurological conditions based on the efficacy of synthetic and endogenous CB1R ligands in animal models of epilepsy, neurodegeneration, addiction, pain, and mood disorders. However, psychotropic side effects limit the translational potential of CB1R modulation via direct pharmacological intervention (Lutz 2009). While CB1R signaling through Gprotein-mediated pathways has been an area of intense investigation, additional CB1R binding proteins that classify as scaffolding or regulatory proteins have been identified as potential modulators of CB1R activity (Smith et al. 2010).

Cannabinoid receptor interacting protein 1a (CRIP1a) interacts with the C-terminal tail of CB1R, as revealed by a yeast two-hybrid screen and by coimmunoprecipitation of CRIP1a with CB1R obtained from rat brain homogenates (Niehaus et al. 2007). CRIP1a is conserved throughout vertebrates and is robustly expressed in the brain. While anatomical data on co-localization in the adult brain is still missing, high-resolution immunohistochemical analysis of CB1R and CRIP1a expression in the developing rodent forebrain showed largely segregated profiles (Keimpema et al. 2010). Ectopic CRIP1a modulates constitutive CB1R activity in isolated cervical ganglion neurons, suggesting that CRIP1a may modulate CB1R signal transduction in an agonist-independent manner in this system (Niehaus et al. 2007). 
While the mechanisms by which CRIP1a exerts its effects on CB1R remain unknown, CRIP1a binds to the C-terminal tail of CB1R (Niehaus et al. 2007), which is essential for CB1R desensitization and internalization (Daigle et al. 2008; Jin et al. 1999; Straiker et al. 2012), indicating a role in modulating receptor activity. A role for CB1R trafficking is also supported by the presence of a PDZ ligand in CRIP1a that could allow indirect crosslinking of CB1R with other PDZ proteins (Howlett et al. 2010).

Recent data showed that CRIP1a expression is altered following epileptiform activity. In the hippocampus of epileptic patients, CB1R and CRIP1a are downregulated (Ludanyi et al. 2008) whereas kainic acid-induced seizures elevate CB1R and CRIP1a levels in the rat hippocampus (Bojnik et al. 2012). Conditional mutagenesis has revealed that $C B 1 R$ in glutamatergic forebrain neurons is essential for the protection against excitotoxic seizures (Marsicano et al. 2003; Monory et al. 2006). Altogether, these data suggest a potential role for CRIP1a as a regulator of CB1Rmediated control of excess neuronal activity. However, the role of CRIP1a in vivo has not been addressed in detail yet.

In this study, we investigated CRIP1a as modulator of CB1R signaling. Specifically, we elucidated CRIP1a localization in the mouse hippocampus and analyzed the effects of CRIP1a on CB1R signaling. 


\section{Materials and Methods}

\section{Animals}

Adult (3-6 months old) male mice were used for all experiments. C57BL/6N mice were purchased from Charles River, Sulzfeld (Germany). Animals were housed in groups of $3-5$ individuals in a temperature- and humidity-controlled room $\left(22^{\circ} \mathrm{C} \pm 1\right.$; $50 \% \pm 1$ ), with a $12 \mathrm{~h}$ light/dark cycle and had access to food and water ad libitum. All experimental procedures were approved by the Committee on Animal Health and Care of local government (Az. 23-177-07/G08-1-021 and Az. 23 177-07/G 10-1-037). $\mathrm{CB} 1^{\text {floxed/floxed;Dlx5/6-Cre/+ }}$ mice (GABA-CB1R-KO) lack the CB1R specifically in GABAergic interneurons and were generated as described (Massa et al. 2010; Monory et al. 2006).

\section{AAV vector generation and administration}

The rat Cnrip1a open reading frame was EcoRI and HindIII-linkered and fused downstream of the hemagglutinin (HA) epitope tag coding region in an $\mathrm{AAV}$ expression cassette containing the $1.1 \mathrm{~kb}$ CMV immediate early enhancer/chicken $\beta$ actin hybrid promoter (CAG), the woodchuck hepatitis virus post-transcriptional regulatory element (WPRE), and the bovine growth hormone polyadenylation sequence (bGHpA) flanked by AAV2 inverted terminal repeats (pAAV-CRIP1a). The same backbone carrying no cDNA was used as control (pAAV-empty). Production of neurotropic AAV1/2 vectors and determination of genomic titres using the $\mathrm{ABI} 7500$ real time PCR cycler (Applied Biosystems) were performed as described (During et al. 2003). Adult male C57BL/6N mice were anaesthetized by intraperitoneal injection of fentanyl $(0.05 \mathrm{mg} / \mathrm{kg})$, midazolam $(5 \mathrm{mg} / \mathrm{kg})$ and medetomidin $(0.5 \mathrm{mg} / \mathrm{kg})$, and fixed in a small animal stereotaxic frame (Kopf instruments, Tujunga, CA). One microliter of either AAV-CRIP1a or AAV-empty $\left(9 \times 10^{10}\right.$ viral genomes $\left./ \mathrm{ml}\right)$ was 
injected bilaterally into the CA1 area of the dorsal hippocampus $(+2.0 \mathrm{~mm} \mathrm{AP}, \pm 1.6$ $\mathrm{mm} \mathrm{ML},-1.3 \mathrm{~mm}$ DV from bregma) at a rate of $150 \mathrm{nl} / \mathrm{min}$ using a microprocessorcontrolled mini-pump with 34G beveled needles (World Precision Instruments, Sarasota, FA).

\section{Immunohistochemistry}

\section{Determination of CRIP1a expression domains}

Mice were perfused with a fixative containing $4 \%$ paraformaldehyde (PFA) and $0.1 \%$ glutaraldehyde in $0.1 \mathrm{M}$ phosphate-buffer ( $\mathrm{PB}, \mathrm{pH}$ 7.4). Brains were removed from the skull and cut $(50 \mu \mathrm{m})$ in the coronal plane on a cryostat after postfixation overnight and subsequent cryoprotection in $30 \%$ sucrose (in PB). Free-floating sections were rinsed in PB and pre-treated with $0.3 \%$ Triton-X 100 (in PB) for $1 \mathrm{~h}$ at $22-24{ }^{\circ} \mathrm{C}$ to enhance the penetration of antibodies. Non-specific immunoreactivity was suppressed by incubating our specimens in a cocktail of $5 \%$ normal donkey serum (NDS; Jackson), $1 \%$ bovine serum albumin (BSA; Sigma) and $0.3 \%$ Triton X100 (Sigma) in PB for $1 \mathrm{~h}$ at $22-24{ }^{\circ} \mathrm{C}$. Sections were exposed $\left(16-72 \mathrm{~h}\right.$ at $4{ }^{\circ} \mathrm{C}$ ) to anti CRIP1a; 1:500, (Keimpema et al., 2010); in select combinations with anti CB1R; 1:1000, (Kawamura et al., 2006), or anti VGluT1 (Synaptic Systems; 1:2000), or anti VGluT3 (Synaptic Systems; 1:1000), or anti GAD65/67 (Sigma; 1:5000), or anti DAGL $\alpha$ (gift from M. Watanabe; 1:5000) diluted in PB, which supplemented to $0.5 \%$ NDS and $0.3 \%$ Triton $\mathrm{X}-100$. After extensive rinsing in $\mathrm{PB}$, immunoreactivities were revealed by carbocyanine (Cy) 2, 3 or 5 -tagged secondary antibodies raised in donkey (1:200 [Jackson], $2 \mathrm{~h}$ at $\left.22-24^{\circ} \mathrm{C}\right)$. Lipofuscin autofluorescence was routinely quenched by applying Sudan Black-B (1\%, dissolved in $70 \%$ ethanol) as described (Schnell et al. 1999). Glass-mounted sections were coverslipped with Aquamount Fluorescent Mounting Medium (Dako). 
Sections processed for multiple immunofluorescence histochemistry were inspected and images acquired on a 700LSM confocal laser-scanning microscope (Zeiss). Image surveys were generated using the tile scan function with optical zoom ranging from $0.6 \mathrm{x}$ to $1.5 \mathrm{x}$ at $10 \mathrm{x}$ primary magnification (objective: EC Plan-Neofluar 10x/0.30). Co-localization was defined as immunosignals being present without physical signal separation in $\leq 0.5-0.7 \mu \mathrm{m}$ optical slices at $40 \mathrm{x}$ (Plan-Neofluar $40 x / 1.30$ ) or $63 x$ (Plan-Apochromat $63 x / 1.40$ ) primary magnification and at optical zoom ranging from $1 \mathrm{x}$ to $3 \mathrm{x}$. Emission spectra for each dye were limited as follows: Cy2 $(505-530 \mathrm{~nm})$, Cy3 $(560-610 \mathrm{~nm})$, and Cy5 $(650-720 \mathrm{~nm})$. Colocalization or immediate neighborhood of the histochemical markers CB1R/CRIP1A were verified by capturing serial orthogonal $z$ images ( $z$ stacks) at $63 x$ primary magnification (pinhole: $20 \mu \mathrm{m}$; 2048x2048 pixel resolution; original $X Z$ and $Y Z$ visualizations in the figure show a $1.7 x$ pixel distortion in the Z-scale). Multi-panel figures were assembled in CorelDraw X5 (Corel Corp.).

Spatial relation between $\mathrm{CB} 1 \mathrm{R}$-immunoreactive $\left({ }^{+}\right)$and $\mathrm{CRIP} 1 \mathrm{a}^{+}$profiles were quantified in vehicle or HU-210 (Tocris Bioscience) treated GABA-CB1R-KO mice (N $=3$ per group) dentate gyrus. Profiles were counted manually within $40 \mu \mathrm{m}^{2}$ large frames ( $\mathrm{N}=15$ per animal) and sorted as follows: (i) profiles with overlap, (ii) profiles with physical contact but without complete overlap, (iii) separate profiles without any contact to neighboring profiles. Spatial relation between $\mathrm{CB} 1 \mathrm{R}^{+}$and $\mathrm{GAD}^{+}$or VGLUT1 $^{+}$or DAGL ${ }^{+}$profiles were quantified in vehicle treated GABA-CB1R-KO mice dentate gyrus under identical conditions.

\section{$A A V$-mediated transgene expression}

At the end of the experiment, the expression pattern of AAV-CRIP1a animals was examined by HA-immunohistochemistry to confirm accurate targeting of the CA1 
target area and robust transgene expression. Brain sections were immunostained for the HA-epitope tag as described (Guggenhuber et al. 2010). Briefly, mice were perfused in $4 \%$ buffered neutral formalin and post-fixed overnight in the same fixative. Free-floating brain sections $(40 \mu \mathrm{m})$ were incubated overnight with a mouse anti-HA antibody (Covance, Richmond, CA; 1:1000). Sections were washed and then incubated for $1 \mathrm{~h}$ with the appropriate Alexa488 or Alexa546-conjugated goat IgG (1:1000, Invitrogen, Eugene, OR). Before the third wash in PBS, sections were counterstained with the nuclear dye 4',6-diamidino-2-phenylindole (DAPI) for $5 \mathrm{~min}$. Sections were then transferred onto glass slides and coverslipped with Mowiol mounting medium and fluorescence was visualized using a Leica DM5500 microscope (Leica Microsystems, Wetzlar, Germany).

\section{In situ hybridization}

Cnr1 riboprobe generation and in situ hybridization was performed as described (Steindel et al. 2013). The mouse Cnrip1a sequence was obtained from a mouse brain cDNA library by PCR using the following primers: $55^{\circ}$ CTCTCCAGCCTTCACTGTCC-3` and 5`-AGGCTTGTGCTGGTTTGTCT-3`. The 608 bp Cnrip1a fragment was inserted in the pBlueskript vector allowing for in vitro transcription using T3 (antisense; BamH1) and T7 (sense; HindIII) RNA polymerases. Mouse brains were removed and immediately frozen on dry ice. Cryostat-cut $18 \mu \mathrm{m}$ coronal sections were collected on poly-L-lysine coated slides before postfixing in $4 \%$ paraformaldehyde in $0.1 \mathrm{M}$ phosphate buffer, $\mathrm{pH}$ 7.4. After dehydration in $100 \%$ ethanol, slides were air-dried before application of $50 \mu \mathrm{l}$ hybridization buffer containing DIG-labeled Cnrip1a riboprobe and FITC-labeled Cnr1 riboprobe. Slides were incubated overnight at $54{ }^{\circ} \mathrm{C}$ with the according riboprobes, then washed three times at $62{ }^{\circ} \mathrm{C}$ for $30 \mathrm{~min}$ in SSC containing $0.05 \%$ Tween20. Sections were blocked 
for $1 \mathrm{~h}$ in $4 \%$ heat-inactivated sheep serum in TNT and incubated for $2 \mathrm{~h}$ with antiFITC(Fab)-POD (Roche, 1:500). Detection was initiated by a 10 min incubation step with tyramine-FITC (1:50). After subsequent washing and blocking steps, slides were exposed overnight to anti-DIG(Fab)-POD (Roche, 1:2000). Afterwards, sections were incubated with tyramine-CY3 (1:50) for $10 \mathrm{~min}$. Cell nuclei were stained with DAPI and slides were embedded with Mowiol mounting medium.

\section{Generation of HEK cell line stably expressing HA-tagged CB1R}

The HA-tag was added N-terminally to the rat CB1R sequence by PCR using the following primers: forward 5'-GCGGA TCCAC CATGG CATAC CCATA TGATG TCCCC GACTA CGCGA AGTCG ATCCT AGATG GCCTTG-3', reverse 5'-GGCGC GGCCG CTCAC AGAGC CTCGG CGGA-3'. The resulting sequence was cloned into the expression vector pcDNA3 using the restriction sites BamHI and Notl. HEK293 cells were grown in DMEM containing $10 \%$ fetal calf serum, Penicillin/Streptamycin, sodium butyrate and non-essential amino acids (life technologies). To generate cell lines stably expressing HA-CB1R, HEK293 cells were transfected with $24 \mu \mathrm{g}$ of linearized DNA in a 10-cm dish using Lipofectamin2000 (Invitrogen) according to the manufacturer`s instructions. $48 \mathrm{~h}$ after transfection, selection medium containing G418 (Geneticin) was added to the cells. A limited dilution approach in 96 well plates was performed to select cell clones resistant to G418. Clones were picked only out of those wells, which originally contained just a single cell. Homogenous HA-CB1R expression was analyzed by immunocytochemistry against the HA epitope. Expression levels of HA-CB1R were further determined by Western blot analysis using a monoclonal antibody against the HA tag. 


\section{Determination of CB1R internalization by trypsination}

HEK293 cells stably expressing N-terminally HA-tagged rat CB1R were been cultivated in 6-well plates for $48 \mathrm{~h}$ before they were transfected with either a CRIP1a or a GFP plasmid using lipofectamine. $24 \mathrm{~h}$ after transfection, cells were exposed to serum-free medium for minimum $3 \mathrm{~h}$ and then stimulated with $\mathrm{HU}-210$ or vehicle (DMSO) for $45 \mathrm{~min}$. To assay intracellular receptors, cells were afterwards incubated with $0.05 \%$ trypsin-EDTA $4 \mathrm{Na}$ ( $\mathrm{pH} 7.4$, Invitrogen) for $4 \mathrm{~min}$ at $\mathrm{RT}$; control cells for comparison were incubated with $0.2 \mathrm{~g} / \mathrm{L}$ EDTA $4 \mathrm{Na}$ alone (Versene, $\mathrm{pH} 7.4$, Invitrogen) as described (Grimsey et al. 2010). Cell lysis was performed overnight at $4^{\circ} \mathrm{C}$ in lysis buffer containing $150 \mathrm{mM} \mathrm{NaCl}, 1 \mathrm{mM}$ EDTA, $1 \mathrm{mM}$ EGTA, $20 \mathrm{mM}$ Tris, $\mathrm{pH} 7.5,1 \%$ CHAPS, proteinase and phosphatase inhibitor. $10 \mu \mathrm{g}$ of protein was applied in the western blot against the HA tag. Densitometric assessment of HA signal on the immunoblot was performed using Bio1D software (Vilber Lourmat, Torcy, France) and data were normalized to tubulin. Due to agonist-independent CB1R internalization and possible variation between experiments and to exclude a possible effect of the different treatments on CB1R expression, the ratio of HU-210induced CB1R internalization was calculated according to the following formula: [(HA signal of cells treated with HU-210 and trypsin/HA signal of cells treated with HU-210 and versene) - (HA signal of cells treated with DMSO and trypsin/HA signal of cells treated with DMSO and versene)] $\times 100.100 \%$ internalization means that all CB1 receptors got internalized after $\mathrm{HU}-210$ stimulation.

\section{Western blot analysis}

Hippocampi of AAV-CRIP1a mice and AAV-empty mice were isolated and homogenized in $1 \mathrm{ml}$ of ice-cold membrane buffer $(50 \mathrm{mM}$ Tris- $\mathrm{HCl}, \mathrm{pH} 7.4,3 \mathrm{mM}$ $\mathrm{MgCl}_{2}, 0.2 \mathrm{mM}$ EGTA, Complete protease inhibitor; Roche). Following determination 
of protein content, aliquots were mixed with an equal volume of $2 x$ Laemmli reducing sample buffer. $10 \mu \mathrm{g}$ of total protein were resolved by $12 \%$ SDS-PAGE and electroblotted onto nitrocellulose membrane. After blocking in $5 \%$ non-fat dry milk, the membrane was incubated with primary antibodies against CRIP1a (17 C-terminal residues) (Niehaus et al. 2007), rabbit anti-HA (Santa Cruz Biotechnology; 1:1000) or rabbit anti-CB1R (Immunogenes; $1: 1000$ ) at $4^{\circ} \mathrm{C}$ overnight. Cell adhesion molecule F3 (kindly provided by Eva-Maria Krämer-Albers) or ß-actin (Sigma; 1:1000) was probed as loading control. Secondary antibodies were horseradish peroxidaseconjugated anti-rabbit or anti-mouse IgG (Dianova). Proteins were detected using a chemiluminescence system (Luminol) and bands captured on film. Densitometric analysis was performed using Bio1D software (Vilber Lourmat) and data were normalized to the loading control.

\section{Agonist-stimulated $\left[{ }^{35} \mathrm{~S}\right] \mathrm{GTP} \gamma \mathrm{S}$ binding}

Hippocampal homogenates including cytosolic proteins $(10 \mu \mathrm{g})$ of AAV-empty and AAV-CRIP1a mice previously analyzed by immunoblot were processed for the binding assay as described (Guggenhuber et al. 2010). The homogenates were incubated with the CB1R agonist, HU-210, for 60 min. Basal binding was measured in the absence of cannabinoid receptor agonists and defined as $0 \%$ in each experiment. All data are expressed as percentage stimulation above basal $\left[{ }^{35}\right.$ S $]$ GTPYS binding.

\section{CB1R stimulation with HU-210}

HU-210 dissolved in DMSO was added to serum-free medium to obtain a final concentration of $100 \mathrm{nM}$. Cells were subjected to HU-210 treatment for $45 \mathrm{~min}$. For in vivo treatment, $\mathrm{HU}-210$ was dissolved in a mixture of DMSO, cremophor and saline 
solution (1:1:18) and was injected intraperitoneally $(50 \mu \mathrm{g} / \mathrm{kg})$ in a volume of $10 \mathrm{ml} / \mathrm{kg}$ body weight to GABA-CB1R-KO mice.

\section{Induction of acute excitotoxic seizures}

Kainic acid (KA; Ascent scientific) dissolved in $0.9 \%$ saline was administered (30 $\mathrm{mg} / \mathrm{kg}$; i.p.) in a volume of $10 \mathrm{ml} / \mathrm{kg}$ body weight to induce epileptiform seizures as described previously (Guggenhuber et al. 2010). Two trained observers blind to the genotype of the mice monitored the severity of seizures for $2 \mathrm{~h}$ and scored every 15 min according to the following scale (Monory et al. 2006): 0 - no response; 1 immobility and staring; 2 - forelimb and/or tail extension, rigid posture; 3 - repetitive movements, head bobbing; 4 - rearing and falling; 5 - continuous rearing and falling: 6 - severe clonic-tonic seizures; 7 - death. One AAV-CRIP1a and one AAV-empty animal were excluded from the study as they they showed no response to kainic acid. The time to onset of seizures was defined by the time to reach seizure score 3 .

\section{Electrophysiological recordings}

For the electrophysiological experiments, we used coronal hippocampal slices of 913 week old mice injected with AAV-empty or AAV-CRIP1a. Mice were deeply anesthetized with enflurane (Ethrane, Abbot Laboratories). After decapitation, brains were quickly removed and immersed for 2-3 min in ice-cold slicing solution containing (in mM): $26 \mathrm{NaHCO}_{3}, 1.2 \mathrm{NaH}_{2} \mathrm{PO}_{5}, 7 \mathrm{MgCl}_{2}, 0.5 \mathrm{CaCl}_{2}, 2 \mathrm{KCl}, 11$ glucose, and 250 $\mathrm{mM}$ sucrose). Subsequently $350 \mu \mathrm{m}$ thick slices were cut on a vibratome (Microm HM650V, Thermo Fisher) and were stored in standard artificial cerebrospinal fluid (ACSF), containing $126 \mathrm{NaCl}, 26 \mathrm{NaHCO}_{3}, 1.25 \mathrm{NaH}_{2} \mathrm{PO}_{5}, 1 \mathrm{MgCl}_{2}, 2 \mathrm{CaCl}_{2}, 2.5$

$\mathrm{KCl}, 15$ glucose, at room temperature, where they were allowed to recover for at least $1 \mathrm{~h}$. For patch recordings, slices were transferred to a recording chamber 
attached to the fixed stage of a microscope (BX51 WI, Olympus), where they were continuously superfused with ACSF at a rate of $2 \mathrm{ml} / \mathrm{min}$ at $30 \pm 1{ }^{\circ} \mathrm{C}$. Pyramidal neurons in the stratum pyramidale of the CA1 region were identified by their location and morphological appearance in infrared differential interference contrast image. Patch-pipettes (3-5 M 2 ) were pulled from borosilicate glass capillaries $(2.0 \mathrm{~mm}$ outside, $1.16 \mathrm{~mm}$ inside diameter, Science Products, Hofheim, Germany) on a vertical puller (PP-830, Narishige) and filled with pipette solution containing (in $\mathrm{mM}$ ): 130 K-gluconate, $10.5 \mathrm{KCl}, 0.2$ EGTA, 10 HEPES, 2 Na2-ATP, 0.5 Na-GTP, 5 QX314 (N-(2,6-Dimethylphenylcarbamoylmethyl)triethylammonium chloride, Sigma), pH adjusted to 7.3 by $\mathrm{KOH}$. Signals were recorded with a discontinuous voltageclamp/current-clamp amplifier (SEC05L, NPI), low-pass filtered at $3 \mathrm{kHz}$ and stored and analyzed using an ITC-1600 AD/DA board (HEKA) and TIDA (Heka) software. Excitatory synaptic inputs were evoked using biopolar tungsten electrodes (impedance 4-5 M $\Omega, F H C$ ) inserted in Schaffer collateral pathways. Stimulation intensity was set to $60-70 \%$ of supramaximal stimulus intensity. All experiments were performed in the continuous presence of $10 \mu \mathrm{M}$ gabazine (6-Imino-3-(4methoxyphenyl)-1(6H)-pyridazinebutanoic acid hydrobromide; Biotrend). To prevent recurrent excitation in the presence of the $\mathrm{GABA}_{\mathrm{A}}$ antagonist gabazine, the connections between CA3 and CA1 were disrupted by a small incision between CA1 and CA3. Membrane potential was held at $-65 \mathrm{mV}$. Paired-pulse ratios were determined at $55 \mathrm{~ms}$ interpulse interval. Depolarization-induced suppression of excitation was investigated according to the protocol described (Ohno-Shosaku et al. 2002) using $5 \mathrm{~s}$ interstimulus intervals and 2-10 s lasting depolarization to 0 $\mathrm{mV}($ Ohno-Shosaku et al. 2002). For the investigation of $\mathrm{HU}-210$ effects on excitatory transmission, stimuli were delivered at $0.066 \mathrm{~Hz}$. DSE magnitude was calculated as follows: $\Delta$ of ePSCs $=[(x 2-x 1) / x 1] * 100$, where $x 1=$ mean of last five ePSC 
amplitudes before depolarization, and $\mathrm{x} 2$ = mean of first three ePSCs amplitudes immediately after the depolarization. A significant deviation from zero was considered as DSE. The effect of HU-210 on EPSCs amplitude was quantified at the last 5 min of drug application and normalized to average baseline EPSCs amplitude. Miniature excitatory postsynaptic currents (mEPSCs) were recorded in the presence of $10 \mu \mathrm{M}$ gabazine and $1 \mu \mathrm{M}$ tetrodotoxin (TTX).

\section{Statistics}

Data are presented as means \pm SEM and were analyzed using unpaired, two-tailed $t$ test or two-way ANOVA for normally distributed variables to evaluate statistical significance with $p<0.05$ as level of statistical significance. Seizure scores were analyzed using repeated measures ANOVA including Greenhouse-Geisser correction or Mann-Whitney $U$ test. For agonist-stimulated $\left[{ }^{35} \mathrm{~S}\right] \mathrm{GTPYS}$ binding, nonlinear regression and sigmoidal curve fitting were used to obtain potency $\left(\mathrm{EC}_{50}\right)$ and efficacy $\left(E_{\max }\right)$ values. A successful induction of DSE was determined by analysis with one-sample $t$ tests. The Kaplan-Meier method was used to evaluate survival, followed by the log rank test to identify significant differences. Graphs were generated with GraphPad Prism 4.0 (GraphPad Software). SPSS 20 software (IBM) and GraphPad were used for statistical analyses. 


\section{Results}

\section{CRIP1a expression in the mouse hippocampus}

CRIP1a is widely distributed in rodent tissues, with the highest expression levels in the brain (Niehaus et al. 2007). However, the expression pattern of CRIP1a in the brain and its relationship with CB1R expression has not been investigated so far. Therefore, we performed fluorescent double in situ hybridization to reveal Cnrip1a and Cnr1 mRNA localization in the mouse brain.

Cnr1 mRNA is found in the forebrain with highest levels in the hippocampus (Marsicano and Lutz 1999). Our results confirmed this finding and revealed a similar distribution of Cnrip1a mRNA, which was predominantly expressed in the cerebral cortex and the hippocampus (Fig. 1A-A“'). Cnrip1a mRNA was detected in principal cells of cornu ammonis (CA) areas 1-3, neurons of stratum radiatum, hilus and in granule cells of the dentate gyrus (Fig. 1B). In situ hybridization using sense probes produced no mRNA signal, confirming the specificity of the antisense probes (not shown). Cnr1 is expressed at very high levels in $\mathrm{CCK}^{+}$GABAergic interneurons and at moderate to low levels in glutamatergic neurons (Kawamura et al. 2006; Marsicano and Lutz 1999). Consistently, we found low levels of Cnr1 mRNA in pyramidal cells of CA1-CA3 and high Cnr1 mRNA levels in interneurons mainly located in the stratum radiatum and in the hilar region (Fig. 1B'). In hippocampal pyramidal cells and hilar cells, Cnrip1a was co-expressed with Cnr1 (Fig. 1B-B“", C-C”, D-D“, G-G”). In the stratum radiatum, virtually all cells expressing high levels of Cnr1 mRNA - a characteristic feature of GABAergic interneurons - were also positive for Cnrip1a mRNA (Fig. 1E-E`; 736 cells/34 hippocampal sections/2 mice). Cnrip1a signal was abundant in dentate gyrus granule cells (Fig. 1F, F“'). In contrast, this cell population lacked Cnr1 mRNA (Fig. 1F'), confirming previous findings (Marsicano and Lutz 1999). In summary, both glutamatergic and GABAergic cell types expressing either 
low or high levels of Cnr1 mRNA show Cnrip1a mRNA co-expression. In contrast to Cnr1, Cnrip1a transcripts were equally abundant in pyramidal neurons and interneurons in the hippocampal formation. The intensity of Cnrip1a mRNA expression varied somewhat among the different subfields with no correlation with Cnr1 mRNA levels.

To investigate CRIP1a protein localization within the hippocampus and its potential interaction with $\mathrm{CB} 1 \mathrm{R}$, we performed immunohistochemistry on coronal mouse brain sections. CRIP1a immunoreactivity was observed throughout the hippocampus, with higher densities in principal cell layers of CA fields and dentate gyrus (Fig. 1H). This pattern was similar to relative densities of CB1R in the corresponding areas (Fig. $\left.1 \mathrm{H}^{\prime}\right)$. However, the subcellular distribution of CRIP1a and CB1R proteins only partly overlapped. Thus, whilst CB1R staining was restricted to terminal axon fibers and endings, CRIP1a immunoreactivity was found in somata or widely distributed in the surrounding neuropil (Fig. 1I), but also in intimate contact (CA1 stratum pyramidale; Fig. 1J) or direct overlap (CA1 stratum radiatum; Fig. 1K,L) with CB1R-expressing processes. These data suggest that CB1Rs are in close proximity to CRIP1a. CRIP1a immunostaining was abolished by pre-absorption of antisera with the CRIP1a antigen peptide, confirming antibody specificity (Keimpema et al. 2010).

Next, we asked whether CRIP1a is associated with both excitatory and inhibitory synapses. Vesicular glutamate transporters are indispensable proteins in excitatory terminal axon segments to control neurotransmitter shuttling in nerve endings (Kaneko et al. 2002). Glutamic acid decarboxylase (GAD) is an enzyme present specifically at inhibitory GABAergic synapses. We identified a large number of CRIP1a ${ }^{+}$loci in direct contact with $\mathrm{GAD}^{+}$, VGluT1 ${ }^{+}$or VGluT3 ${ }^{+}$compartments in stratum radiatum (Fig. 2) or the hilus (Supplementary Fig. 1A,B). The close relation of CRIP1a and synaptic proteins suggests that CRIP1a is present in both excitatory and 
inhibitory terminals. The major CB1R ligand 2-arachidonoylglycerol is produced by the enzyme diacylglycerol lipase- $\alpha$ (DAGL $\alpha)$, which is typically located postsynaptically (Kano et al. 2009; Yoshida et al. 2006). DAGLa ${ }^{+}$and CRIP1a ${ }^{+}$ profiles appeared to be juxtaposed in stratum radiatum (Fig. 2) and hilus, (Supplementary Fig. 1C), indicating that CRIP1a is confined to the presynaptic compartment. To further test this, we quantitatively analyzed the ratio of CRIP1a ${ }^{+}$ profiles contacting VGluT1 ${ }^{+}, \mathrm{GAD}^{+}$or $\mathrm{DAGL} \alpha^{+}$puncta (Fig. 2). $84.1 \pm 4.7 \%$ of all CRIP1 $a^{+}$profiles directly contacted or overlapped with VGluT1 ${ }^{+}$and $\mathrm{GAD}^{+}$terminals, but only $7.3 \pm 1.2 \%$ of them with $\mathrm{DAGL \alpha}^{+}$profiles which strongly suggests the presynaptic localization of CRIP1a within the synaptic domain.

\section{Convergence of CB1R with CRIP1a following CB1R stimulation in vivo}

We have shown that at the subcellular level CB1R protein is in intimate proximity to but does not fully overlap with CRIP1a under basal conditions. To reconcile this observation with the proposed physical interaction of CRIP1a with CB1R (Niehaus et al. 2007), we asked whether the subcellular localization of CB1R and CRIP1a in mossy cells, which are implicated in excessive activity during seizures, might change by stimulation of CB1R. To address this question, we mapped the spatial relation of $\mathrm{CB}_{1} \mathrm{R}^{+}$and $\mathrm{CRIP} 1 \mathrm{a}^{+}$profiles in mossy cell termini, located in the inner molecular layer of the dentate gyrus, of mice lacking CB1R in GABAergic neurons (GABACB1R-KO) treated with either vehicle or the CB1R agonist HU-210.

We used mice lacking CB1R in GABAergic neurons to diminish extensive CB1R staining derived from GABAergic cells and to quantitatively assess glutamatergic $\mathrm{CB} 1 \mathrm{R}^{+}$and $\mathrm{CRIP} 1 \mathrm{a}^{+}$profiles (15 sections/animal; 3 mice/group). Only a minority of CRIP1a ${ }^{+}$profiles completely overlapped with CB1R, which did not change after HU210 treatment (Fig. 3). However, CB1R stimulation caused a significant increase in 


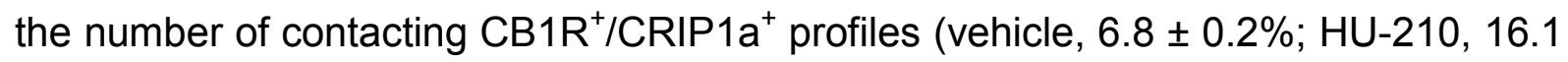
$\pm 2.4 \% ; p=0.017$ ). Concomitantly, we observed a trend towards decrease physically separated profiles that failed to reach statistical significance (vehicle, $89.3 \pm 1.5 \%$; $\mathrm{HU}-210,81.9 \pm 2.3 \% ; p=0.056)$. This finding indicates that CB1R activation causes rearrangement of CRIP1a and CB1 protein clusters in glutamatergic neurons.

\section{CRIP1a affects CB1R internalization}

CRIP1a binds to the C-terminal tail of CB1R (Niehaus et al. 2007), which plays an essential role in CB1R desensitization and internalization (Daigle et al. 2008; Jin et al. 1999; Straiker et al. 2012). We therefore hypothesized that co-expression of CRIP1a with activated CB1R may interfere with receptor internalization. To address this, we used HEK293 cells stably expressing N-terminally HA-tagged CB1R, for a transient transfection with a plasmid encoding either CRIP1a or GFP (control) and performed an internalization assay (see Methods). Transfected cells were stimulated with HU-210 (100 $\mathrm{nM}$ ) or vehicle for $45 \mathrm{~min}$ and treated with trypsin or versene (control). Trypsin recognizes a cleavage site in the extracellular tail of CB1R and dissociates the HA tag from the recombinant receptor. Since trypsin is incapable of entering intact cells, the levels of HA-CB1R detected by immunoblotting can be directly attributed to the amount of internalized recombinant receptor (Fig. 4). CB1R stimulation resulted in $27.9 \pm 1.8 \%(\mathrm{~N}=6)$ of receptor being internalized. The presence of CRIP1a resulted in significantly less CB1R internalization $(19.4 \pm 2.9 \%$; $p<0.05)$. This result is likely a conservative reflection of CRIP1a effects considering transfection efficiencies were only approximately $50-70 \%$. In summary, these data suggest that co-expression of CRIP1a with activated CB1R slows internalization. 


\section{CRIP1a overexpression in the hippocampus}

To determine the effects of CRIP1a on CB1R function in vivo, we employed adenoassociated virus (AAV)-mediated gene transfer to chronically increase CRIP1a levels in hippocampal neurons. Our AAV-expression cassette contained the cytomegalovirus enhancer/chicken beta actin (CAG) promoter known to drive high levels of transgene expression specifically in neurons (von Jonquieres et al. 2013). The HA-tagged CRIP1a cDNA was packaged, and the vector (AAV-CRIP1a) was stereotaxically delivered to the hippocampus of C57BL/6N mice (Fig. 5A). C57BL/6N mice receiving an $A A V$ carrying no cDNA (Fig. 5B) served as control group (AAVempty). The injection site was selected to target transgene expression to $C B 1 R^{+}$ neurons and therefore excluded dentate gyrus granule cells from AAV transduction, which are known to lack CB1R expression (Marsicano and Lutz 1999; Monory et al. 2006). Four weeks after vector delivery, when AAV-mediated transgene expression peaks to remain at stable levels, mice were killed and brains subjected to HAimmunohistochemistry. Recombinant CRIP1a was found in CA1-CA3 of AAV-CRIP1a animals (Fig. 5A) but not in controls (Fig. 5B), and was co-expressed with CB1R in principal neurons of CA1 (Fig. 5C). In AAV-CRIP1a mice, granule cells of the dentate gyrus did not show AAV transgene expression (Fig. 5D). Consistent with our previous studies (Guggenhuber et al. 2010) the rostro-caudal vector spread was $>2.5 \mathrm{~mm}$ and was restricted to the hippocampus (Fig. 5E).

\section{CRIP1a overexpression elevates cannabinoid-induced G protein activation}

We quantified CRIP1a protein expression in hippocampal homogenates of AAVempty and AAV-CRIP1a mice by western blot analysis using antibodies against CRIP1a and the HA tag (Fig. 5F). Size separation by PAGE followed by immunoblot analysis using a CRIP1a antibody allowed simultaneous detection of both 
endogenous (18.6 kDa) and transgenic (20.3 kDa) CRIP1a (Fig. 5F). As expected, endogenous but not recombinant CRIP1a was detected in AAV-empty mice, while both CRIP1a populations were expressed in AAV-CRIP1a mice. Densitometric analysis revealed significantly elevated CRIP1a protein levels in AAV-CRIP1a mice as compared with AAV-empty controls (Fig. 5G; AAV-empty, $95.3 \pm 1.2 \%$; AAVCRIP1a, $151.9 \pm 10.4 \% ; p=0.002$ ). The levels of CB1R were similar in both groups $(p=0.314)$.

Increased CRIP1a levels in hippocampal neurons might affect CB1R signaling, and therefore also CB1R-mediated G protein activation. To address this, we performed a HU-210-stimulated $\left[{ }^{35}\right.$ S]GTP $\gamma$ S binding assay using hippocampal homogenates of AAV-empty and AAV-CRIP1a mice previously analyzed by immunoblot. AAV-empty mice reached a maximum HU-210-induced G protein activation of $52.3 \pm 2.1 \%$ (Fig. $5 \mathrm{H}$ ), while $\mathrm{G}$ protein stimulation in AAV-CRIP1a mice was significantly elevated to a maximum of $74.0 \pm 2.2 \%$ (two-way ANOVA, interaction effect $F(9,130)=2.65, p=$ 0.007 ; genotype effect $F(1,130)=50.49 ; p<0.0001)$. These results suggest that CRIP1a increases CB1R activity by enhancing cannabinoid-induced $G$ protein activation.

\section{Elevated CRIP1a levels do not affect basal CB1R-mediated short-term plasticity} but prolong agonist-induced CB1R signaling

As CRIP1a overexpression resulted in enhanced CB1R-mediated G protein activation, we investigated if depolarization-induced suppression of excitation (DSE) was altered in AAV-CRIP1a mice. Evoked excitatory postsynaptic currents (eEPSCs) were recorded in hippocampal CA1 pyramidal neurons upon Schaffer collateral stimulation, and a DSE protocol was applied. While a $2 \mathrm{~s}$ postsynaptic depolarization did not affect the eEPSC amplitudes (7 cells from AAV-empty and 10 cells from AAV- 
CRIP1a mice), a $5 \mathrm{~s}$ postsynaptic depolarization reduced eEPSCs significantly $(p<$ 0.05 ) in neurons from AAV-empty mice to $93.9 \pm 0.5 \%$ ( 11 cells, 4 mice) and in AAVCRIP1a mice to $95.4 \pm 0.5 \%$ (10 cells, 4 mice). A 10 s postsynaptic depolarization significantly $(p<0.001)$ reduced eEPSCs in neurons from AAV-empty mice $(86.8 \pm$ $2.6 \%, 11$ cells; 6 mice) and AAV-CRIP1a animals ( $84.8 \pm 1.5 \%, 12$ cells; 6 mice) (Fig. 6A). DSE magnitudes did not differ statistically between AAV-empty and AAVCRIP1a mice for both $5 \mathrm{~s}$ postsynaptic depolarization $(-6.1 \pm 0.5 \%, 11$ cells vs. $-5.5 \pm$ $0.5 \%, 10$ cells; $p=0.79$, respectively) and $10 \mathrm{~s}$ postsynaptic depolarization $(-13.2 \pm$ $2.6 \%, 11$ cells vs. $-15.5 \pm 1.4 \%, 12$ cells; $p=0.44$ ) (Fig. 6B). These results indicate that CRIP1a neither affects basal CB1R activity nor alters the stimulation strength required for DSE induction, suggesting that under these conditions CRIP1a does not interfere with excitatory transmission. To identify functional correlates for the reduced CB1R internalization by CRIP1a as well as for the enhanced HU-210 induced $\left[{ }^{35}\right.$ S $]$ GTPYS binding, we next analyzed the depression of eEPSCs in AAV-empty and AAV-CRIP1a mice after bath application of HU-210 (1 $\mu \mathrm{M})$. To evoke responses without causing desensitization over the course of the experiment, we applied a subthreshold dose of HU-210 (1 $\mu \mathrm{M})$, which resulted in a lack of significant depression of eEPSCs in AAV-empty controls (Fig. 6C). In contrast, in AAV-CRIP1a mice a substantial eEPSC depression was observed in the presence of $1 \mu \mathrm{M} \mathrm{HU}-210$, which was larger than in AAV-empty controls when analyzed after 55 min HU-210 incubation (Fig. 6D; AAV-empty, $18.0 \pm 5.9 \%$; AAV-CRIP1a, $53.3 \pm 9.5 \%$; $n=4$ cells, $\mathrm{N}=4$ mice; $\mathrm{p}=0.020)$. Altogether, these findings provide functional evidence that CRIP1a overexpression does not affect short-term CB1R signaling, but enhanced agonist-induced CB1R signaling. 


\section{CRIP1a overexpression increases protection against KA-induced seizures}

The endocannabinoid system exerts an important function in protection against chemically-induced excitotoxic seizures (Marsicano et al. 2003), and acute treatment of kainic acid elevates CB1R and CRIP1a levels in the rat hippocampus (Bojnik et al. 2012). This provided the rationale to investigate the therapeutic potential of CRIP1a overexpression in the context of the pathological consequences of experimentally induced seizures. AAV-empty and AAV-CRIP1a mice received systemic kainic acid (KA, $30 \mathrm{mg} / \mathrm{kg}$ ) injections to induce robust activation of excitatory pathways resulting in acute epileptiform seizures. AAV-CRIP1a mice exhibited a reduced seizure severity as compared to AAV-empty control animals during the course of the experiment (Fig. 7A; genotype effect $F(1,44)=4.18 ; p=0.047)$. The time to reach seizure severity score 3 was not different between the two groups (Fig. 7B). The most advanced seizure stage of every individual mouse during the course of the experiment is described as the maximum behavioral score. This value was significantly lower in AAV-CRIP1a mice than in AAV-empty controls (Fig. 7C; AAVempty, $4.8 \pm 0.3 ;$ AAV-CRIP1a, $4.0 \pm 0.2 ; p=0.044)$. The progression of severe KAinduced seizures can be lethal. Kaplan-Meier survival analysis illustrated a trend towards increased survival rate of AAV-CRIP1a animals in the course of the KA treatment without reaching statistical significance (Fig. 7D; $p=0.089$ ). 120 min after KA-injection, $95.6 \%$ of AAV-CRIP1a mice versus $78.3 \%$ of control animals had survived the experiment. This reduced seizure severity could not be attributed to a reduction of excitatory synaptic transmission, since miniature EPSCs (mEPSCs) did not significantly $(p=0.13)$ differ in their amplitudes between AAV-empty $(10.1 \pm 0.6$ pA, 13 cells, 5 mice) and AAV-CRIP1a ( $8.9 \pm 0.4$ pA, 18 cells, 5 mice $)$ mice (Supplementary Fig. 2A). Furthermore, mEPSCs frequency $(0.18 \pm 0.02 \mathrm{~Hz}$ vs. 0.12 $\pm 0.02 ; p=0.11)$ and paired-pulse ratio of evoked EPSCs $(1.49 \pm 0.09, n=13$ vs. 
$1.44 \pm 0.07 ; p=0.67)$ were also not significantly different between AAV-empty and AAV-CRIP1a mice (Supplementary Fig. 2B-D). Prior to the KA model of epilepsy, AAV-CRIP1a mice, and the respective controls, were subjected to behavioral tests, suggesting that CRIP1a overexpression in hippocampal neurons had no effect on locomotion and inherent anxiety (Supplementary Fig. 3). These findings indicate that increased CRIP1a levels in hippocampal neurons diminish the severity of acute epileptiform seizures, broadly without affecting aspects of emotional and motor behavior. 


\section{Discussion}

The hippocampus is involved in the development of epilepsy, and hippocampal CB1R is essential to provide protection against epileptiform seizures (Marsicano et

al. 2003; Monory et al. 2006). In this report, we demonstrate that the CB1R interacting protein CRIP1a is expressed at high levels in the hippocampus. CRIP1a and CB1R are co-expressed in the major fields of the hippocampal formation, including GABAergic interneurons and glutamatergic pyramidal neurons. Of note, dentate gyrus granule cells are known to lack CB1R expression (Marsicano and Lutz 1999; Monory et al. 2006), but show high levels of CRIP1a. At the subcellular level, CRIP1a and CB1R protein showed different degrees of co-localization, which was minimal in mossy fibre terminals under basal conditions. However, acute CB1R stimulation increased the proportion of CRIP1a/CB1R contacting profiles in mossy fibre terminals, indicating the movement of CRIP1a and CB1R following receptor activation. This finding suggests that CRIP1a interaction with CB1R is regulated by agonist stimulation, which is a common mechanism of modulating GPCR signaling by interacting proteins (Ritter and Hall 2009). Our experiments suggest that CB1R and CRIP1a are presynaptic proteins, yet they did not resolve single CB1R molecules. Therefore, we believe that clusters of molecules move (= traffic) on HU-210 stimulation. The dynamics of lateral movements of molecules in membranes would be in line with our observed relocalization of these clusters within minutes. In fact, CB1R movements upon pharmacological stimuli, as revealed by quantum dot tracking, have been described (Mikasova et al. 2008), suggesting rapid changes in cell surface distribution.

Niehaus and colleagues reported that CRIP1a associates with the CB1R C-terminus, and that the last 14 amino acids of the C-terminal tail of CB1R (aa 460-473) are sufficient to interact with CRIP1b, a shorter CRIP1 splice isoform, exclusively found in 
primates (Niehaus et al. 2007). The C-terminal tail of CB1R is essential for CRIP1a binding because CRIP1a and CRIP1b share the first two exons of the Cnrip1a gene, which encode the minimal domain required for CB1R interaction (Niehaus et al. 2007).

In the present study, we showed that HU-210-induced CB1R internalization in HEK293 cells was reduced when CRIP1a was co-expressed. Interestingly, the distal C-terminal region of $\mathrm{CB} 1 \mathrm{R}$ is also involved in $\beta$-arrestin binding, which is known to modulate GPCR signaling (Daigle et al. 2008). In general, agonist-induced activation of a GPCR induces the phosphorylation of the receptor's cytoplasmic tail by G protein-coupled receptor kinase (GRK), which causes the recruitment of $\beta$-arrestin. $\beta$ arrestin binding to the C-terminal tail of a GPCR results in functional uncoupling from its $\mathrm{G}$ protein, which is referred to as receptor desensitization, and eventually leads to receptor internalization (Reiter and Lefkowitz 2006). Hence, CRIP1a and $\beta$-arrestin may compete to interact with the CB1R C-terminal tail after CB1R stimulation. However, slowed internalization could be due to other interactions such as a general impaired trafficking of membrane proteins, speeding of proteolytic degradation of internalized receptor.

In their pioneering study, Niehaus and colleagues suggested that CRIP1a blocks basal activity of CB1R (Niehaus et al. 2007). The suggested mechanism entailed CRIP1a-dependent suppression of the tonic inhibition of voltage-gated $\mathrm{Ca}^{2+}$ channels by $\mathrm{CB} 1 \mathrm{R}$ in cultured superior cervical ganglion neurons. However, $\mathrm{Ca}^{2+}$ channel inhibition by agonist stimulation of CB1R is not changed in the presence of CRIP1a (Niehaus et al. 2007). In line with that, our data showed that CRIP1a did not interfere with short-term activity or protein levels of CB1R in CA1 pyramidal neurons because DSE magnitudes were not affected by CRIP1a overexpression. DSE protocols utilize the short-term depression of excitatory currents via activation of CB1R by 
endocannabinoids, which were produced and released on demand in response to depolarization (Ohno-Shosaku et al. 2002). However, we observed that long-term CB1R stimulation causes CRIP1a to modulate CB1R signaling in an activitydependent fashion. This finding implies that CRIP1a regulates CB1R activity in an agonist-dependent manner contrary to the conclusion of Niehaus and colleagues. This discrepancy might be due to the usage of different model systems (cultured sympathetic neurons vs. hippocampal slices) and the experimental design (acute vs. long-term CRIP1a-dependent modulation of CB1R downstream signaling).

A recent study investigated the effect of AAV-mediated overexpression of CRIP1a in the rat striatum on CB1R expression (Blume et al. 2013). CRIP1a overexpression had no effect on Cnr1 mRNA and CB1R protein levels, but affected the levels of phosphorylated extracellular signal-regulated kinase (ERK), indicating that CRIP1a may modulate CB1R signaling. In line with our data, Blume and colleagues showed substantial CRIP1a overexpression at the mRNA level but only 1.5 -fold at the protein level (Fig. 5).

The endocannabinoid system constitutes a promising target to attenuate excitotoxic events and to treat neurodegenerative diseases. However, direct pharmacological activation of CB1R causes psychotropic side effects limiting the benefit-to-risk ratio of this treatment (Lutz 2009; Pertwee 2012). Therefore, fine-tuning of CB1R activity in specific brain regions or in specific cell types by modulating CB1R interactions with other proteins would be a promising approach as the distinct effects of CB1R signaling might be caused by molecular differences in the constituents within the pool of CB1R interacting proteins. It is known that CB1R and CRIP1a are downregulated in sclerotic tissue of the hippocampus of epileptic patients (Ludanyi et al. 2008), but acute KA-treatment elevates CB1R and CRIP1a levels in the rat hippocampus (Bojnik et al. 2012). Both these studies suggest that chronic and acute seizure 
activity have different consequences on CRIP1a and CB1R, they also indicate that the expression of both CB1R and CRIP1a are tightly co-regulated and respond to pathological incidents in tandem.

Hippocampal CRIP1a overexpression did not affect locomotion and anxiety-related behavior suggesting that facilitating CB1R/CRIP1a interaction might not result in psychotropic side effects under basal conditions. However, an impairment of CB1R desensitization by CRIP1a overexpression may hypothetically lead to enhanced CB1R signaling in response to excessive excitatory transmission, which would be beneficial for the treatment of neurological disorders such as epilepsy. In fact, we found that elevated CRIP1a levels were sufficient to improve protection against KAinduced seizures. Acute KA application causes long-term activation of glutamatergic transmission, which leads to the development of paroxysmal seizures (Ben-Ari and Cossart 2000). In addition, KA triggers endocannabinoid production (Lourenco et al. 2011; Marsicano et al. 2003). It is well-established that CB1R signaling in glutamatergic, but not in GABAergic, neurons is essential to provide protection against epileptiform seizures (Marsicano et al. 2003; Monory et al. 2006). The protective effect of CRIP1a overexpression against KA-induced seizures cannot be explained by a down-regulation of presynaptic glutamate release or postsynaptic glutamate receptors, since our electrophysiological experiments revealed no effects of CRIP1a over-expression on mEPSCs frequency, mEPSCs amplitude, and pairedpulse ratio of evoked EPSCs. Long-term CB1R activation causes CB1R desensitization, and therefore, reduces CB1R signaling (Jin et al. 1999; Kouznetsova et al. 2002; Straiker et al. 2012). While the AAV system used in this study was not designed to limit CRIP1a transgene expression to glutamatergic neurons, our DSE data (examining solely glutamatergic CB1R activation) and desensitization data (measuring glutamatergic transmission expressed as changes of EPSCs), suggests a 
novel functional role for CRIP1a/CB1R interactions at excitatory synapses in the hippocampus. In conclusion, we hypothesize that by reducing CB1R desensitization in glutamatergic hippocampal neurons, CRIP1a prolongs CB1R signaling which results in an extended suppression of glutamate release. 


\section{Acknowledgements}

This work was supported by the Deutsche Forschungsgemeinschaft FOR926 (subprojects SP3 to B.L. and K.M.), SFB 1080 (subprojects A1 to H.J.L. and B8 to

B.L.), the Australian Research Council (Future Fellowship to M.K.), the Swedish Medical Research Council and the Novo Nordisk Foundation (T.H.). We thank Ruth Jelinek for excellent help with vector production. We are grateful to Ken Mackie and Deborah Lewis for the CRIP1a antibodies and the rat Cnrip1a cDNA.

\section{Conflict of interest}

The authors declare that they have no conflict of interest. 


\section{References}

Ben-Ari Y, Cossart R (2000) Kainate, a double agent that generates seizures: two decades of progress. Trends Neurosci 23 (11):580-587

Blume LC, Bass CE, Childers SR, Dalton GD, Roberts DC, Richardson JM, Xiao R, Selley DE, Howlett AC (2013) Striatal CB1 and D2 receptors regulate expression of each other, CRIP1A and delta opioid systems. J Neurochem 124 (6):808-820. doi:10.1111/jnc.12139

Bojnik E, Turunc E, Armagan G, Kanit L, Benyhe S, Yalcin A, Borsodi A (2012) Changes in the cannabinoid (CB1) receptor expression level and G-protein activation in kainic acid induced seizures. Epilepsy Res 99 (1-2):64-68. doi:10.1016/j.eplepsyres.2011.10.020

Daigle TL, Kwok ML, Mackie K (2008) Regulation of CB1 cannabinoid receptor internalization by a promiscuous phosphorylation-dependent mechanism. J Neurochem 106 (1):70-82. doi:10.1111/j.1471-4159.2008.05336.x

During MJ, Young D, Baer K, Lawlor P, Klugmann M (2003) Development and optimization of adeno-associated virus vector transfer into the central nervous system. Methods Mol Med 76:221-236

Grimsey NL, Graham ES, Dragunow M, Glass M (2010) Cannabinoid Receptor 1 trafficking and the role of the intracellular pool: implications for therapeutics. Biochem Pharmacol 80 (7):1050-1062. doi:10.1016/j.bcp.2010.06.007

Guggenhuber S, Monory K, Lutz B, Klugmann M (2010) AAV vector-mediated overexpression of CB1 cannabinoid receptor in pyramidal neurons of the hippocampus protects against seizure-induced excitoxicity. PLoS One 5 (12):e15707. doi:10.1371/journal.pone.0015707 
Howlett AC, Blume LC, Dalton GD (2010) CB(1) cannabinoid receptors and their associated proteins. Curr Med Chem 17 (14):1382-1393

Jin W, Brown S, Roche JP, Hsieh C, Celver JP, Kovoor A, Chavkin C, Mackie K (1999) Distinct domains of the CB1 cannabinoid receptor mediate desensitization and internalization. The Journal of neuroscience : the official journal of the Society for Neuroscience 19 (10):3773-3780

Kaneko T, Fujiyama F, Hioki H (2002) Immunohistochemical localization of candidates for vesicular glutamate transporters in the rat brain. J Comp Neurol $444(1): 39-62$

Kano M, Ohno-Shosaku T, Hashimotodani Y, Uchigashima M, Watanabe M (2009) Endocannabinoid-mediated control of synaptic transmission. Physiological reviews 89 (1):309-380. doi:10.1152/physrev.00019.2008

Katona I, Freund TF (2012) Multiple functions of endocannabinoid signaling in the brain. Annu Rev Neurosci 35:529-558. doi:10.1146/annurev-neuro-062111150420

Kawamura Y, Fukaya M, Maejima T, Yoshida T, Miura E, Watanabe M, OhnoShosaku T, Kano M (2006) The CB1 cannabinoid receptor is the major cannabinoid receptor at excitatory presynaptic sites in the hippocampus and cerebellum. The Journal of neuroscience : the official journal of the Society for Neuroscience 26 (11):2991-3001. doi:10.1523/JNEUROSCI.4872-05.2006

Keimpema E, Barabas K, Morozov YM, Tortoriello G, Torii M, Cameron G, Yanagawa Y, Watanabe M, Mackie K, Harkany T (2010) Differential subcellular recruitment of monoacylglycerol lipase generates spatial specificity of 2arachidonoyl glycerol signaling during axonal pathfinding. The Journal of neuroscience : the official journal of the Society for Neuroscience 30 (42):13992-14007. doi:10.1523/JNEUROSCI.2126-10.2010 
Kouznetsova M, Kelley B, Shen M, Thayer SA (2002) Desensitization of cannabinoidmediated presynaptic inhibition of neurotransmission between rat hippocampal neurons in culture. Mol Pharmacol 61 (3):477-485

Lourenco J, Matias I, Marsicano G, Mulle C (2011) Pharmacological activation of kainate receptors drives endocannabinoid mobilization. The Journal of neuroscience : the official journal of the Society for Neuroscience 31 (9):32433248. doi:10.1523/JNEUROSCI.3512-10.2011

Ludanyi A, Eross L, Czirjak S, Vajda J, Halasz P, Watanabe M, Palkovits M, Magloczky Z, Freund TF, Katona I (2008) Downregulation of the CB1 cannabinoid receptor and related molecular elements of the endocannabinoid system in epileptic human hippocampus. The Journal of neuroscience : the official journal of the Society for Neuroscience 28 (12):2976-2990. doi:10.1523/JNEUROSCI.4465-07.2008

Lutz B (2009) Endocannabinoid signals in the control of emotion. Curr Opin Pharmacol 9 (1):46-52. doi:10.1016/j.coph.2008.12.001

Marsicano G, Goodenough S, Monory K, Hermann H, Eder M, Cannich A, Azad SC, Cascio MG, Gutierrez SO, van der Stelt M, Lopez-Rodriguez ML, Casanova E, Schutz G, Zieglgansberger W, Di Marzo V, Behl C, Lutz B (2003) CB1 cannabinoid receptors and on-demand defense against excitotoxicity. Science 302 (5642):84-88. doi:10.1126/science.1088208

Marsicano G, Lutz B (1999) Expression of the cannabinoid receptor CB1 in distinct neuronal subpopulations in the adult mouse forebrain. The European journal of neuroscience 11 (12):4213-4225

Massa F, Mancini G, Schmidt H, Steindel F, Mackie K, Angioni C, Oliet SH, Geisslinger G, Lutz B (2010) Alterations in the hippocampal endocannabinoid system in diet-induced obese mice. The Journal of neuroscience : the official 
journal of the Society for Neuroscience $30 \quad$ (18):6273-6281. doi:10.1523/JNEUROSCI.2648-09.2010

Mechoulam R, Parker LA (2013) The endocannabinoid system and the brain. Annu Rev Psychol 64:21-47. doi:10.1146/annurev-psych-113011-143739

Mikasova L, Groc L, Choquet D, Manzoni OJ (2008) Altered surface trafficking of presynaptic cannabinoid type 1 receptor in and out synaptic terminals parallels receptor desensitization. Proceedings of the National Academy of Sciences of the United States of America 105 (47):18596-18601. doi:10.1073/pnas.0805959105

Monory K, Massa F, Egertova M, Eder M, Blaudzun H, Westenbroek R, Kelsch W, Jacob W, Marsch R, Ekker M, Long J, Rubenstein JL, Goebbels S, Nave KA, During M, Klugmann M, Wolfel B, Dodt HU, Zieglgansberger W, Wotjak CT, Mackie K, Elphick MR, Marsicano G, Lutz B (2006) The endocannabinoid system controls key epileptogenic circuits in the hippocampus. Neuron 51 (4):455-466. doi:10.1016/j.neuron.2006.07.006

Nguyen PT, Schmid CL, Raehal KM, Selley DE, Bohn LM, Sim-Selley LJ (2012) beta-arrestin2 regulates cannabinoid CB1 receptor signaling and adaptation in a central nervous system region-dependent manner. Biol Psychiatry 71 (8):714-724. doi:10.1016/j.biopsych.2011.11.027

Niehaus JL, Liu Y, Wallis KT, Egertova M, Bhartur SG, Mukhopadhyay S, Shi S, He H, Selley DE, Howlett AC, Elphick MR, Lewis DL (2007) CB1 cannabinoid receptor activity is modulated by the cannabinoid receptor interacting protein CRIP 1a. Mol Pharmacol 72 (6):1557-1566. doi:10.1124/mol.107.039263

Ohno-Shosaku T, Tsubokawa H, Mizushima I, Yoneda N, Zimmer A, Kano M (2002) Presynaptic cannabinoid sensitivity is a major determinant of depolarizationinduced retrograde suppression at hippocampal synapses. The Journal of 
neuroscience : the official journal of the Society for Neuroscience 22 (10):3864-3872. doi:20026387

Pertwee RG (2012) Targeting the endocannabinoid system with cannabinoid receptor agonists: pharmacological strategies and therapeutic possibilities. Philos $\begin{array}{lllllll}\text { Trans } & \mathrm{R} & \text { Soc Lond } & \text { B Biol Sci } 367 & \text { (1607):3353-3363. }\end{array}$ doi:10.1098/rstb.2011.0381

Reiter E, Lefkowitz RJ (2006) GRKs and beta-arrestins: roles in receptor silencing, trafficking and signaling. Trends Endocrinol Metab 17 (4):159-165. doi:10.1016/j.tem.2006.03.008

Ritter SL, Hall RA (2009) Fine-tuning of GPCR activity by receptor-interacting proteins. Nat Rev Mol Cell Biol 10 (12):819-830. doi:10.1038/nrm2803

Schnell SA, Staines WA, Wessendorf MW (1999) Reduction of lipofuscin-like autofluorescence in fluorescently labeled tissue. The journal of histochemistry and cytochemistry : official journal of the Histochemistry Society 47 (6):719730

Smith TH, Sim-Selley LJ, Selley DE (2010) Cannabinoid CB1 receptor-interacting proteins: novel targets for central nervous system drug discovery? $\mathrm{Br} \mathrm{J}$ Pharmacol 160 (3):454-466. doi:10.1111/j.1476-5381.2010.00777.x

Steindel F, Lerner R, Haring M, Ruehle S, Marsicano G, Lutz B, Monory K (2013) Neuron-type specific cannabinoid-mediated $G$ protein signalling in mouse hippocampus. J Neurochem 124 (6):795-807. doi:10.1111/jnc.12137

Straiker A, Wager-Miller J, Mackie K (2012) The CB1 cannabinoid receptor Cterminus regulates receptor desensitization in autaptic hippocampal neurones. Br J Pharmacol 165 (8):2652-2659. doi:10.1111/j.1476-5381.2011.01743.x

von Jonquieres G, Mersmann N, Klugmann CB, Harasta AE, Lutz B, Teahan O, Housley GD, Frohlich D, Kramer-Albers EM, Klugmann M (2013) Glial 
promoter selectivity following AAV-delivery to the immature brain. PLoS One 8 (6):e65646. doi:10.1371/journal.pone.0065646

Yoshida T, Fukaya M, Uchigashima M, Miura E, Kamiya H, Kano M, Watanabe M (2006) Localization of diacylglycerol lipase-alpha around postsynaptic spine suggests close proximity between production site of an endocannabinoid, 2arachidonoyl-glycerol, and presynaptic cannabinoid CB1 receptor. The Journal of neuroscience : the official journal of the Society for Neuroscience 26 (18):4740-4751. doi:10.1523/JNEUROSCI.0054-06.2006 


\section{Figure legends}

Figure 1. CRIP1a expression in the mouse hippocampus. A-A", Cnrip1a and Cnr1 mRNA in a coronal mouse brain section, as detected by in situ hybridization. Note the high levels of both Cnrip1a and Cnr1 mRNA in the hippocampus and cortex. B-B", In situ hybridization revealed Cnrip1a and Cnr1 mRNA in the hippocampus. Cnrip1a mRNA was detected in pyramidal neurons of the cornu ammonis (CA) areas, in dentate gyrus granule cells and in cells of the stratum radiatum. C-C", D-D", High power magnification of CA3 (C-C") and the hilar region (D-D") shows glutamatergic neurons co-expressing Cnrip1a and Cnr1 mRNA. Note the high levels of Cnrip1a mRNA as compared to the relatively low levels of Cnr1 mRNA. E-E", Interneurons in the stratum radiatum express high levels of Cnr1 mRNA. 100\% of these cells coexpress Cnrip1a mRNA (736 cells/34 hippocampal sections/2 mice). F-F", Granule cells of the dentate gyrus exhibit Cnrip1a mRNA staining but lack Cnr1 mRNA. G-G", CA1 pyramidal cells express moderate Cnrip1a mRNA levels together with low levels of Cnr1 mRNA. H-H", Distribution of CRIP1a and CB1R immunoreactive profiles in the hippocampal formation. CRIP1a immunoreactivity occurred both in a large number of cell bodies and the surrounding neuropil in a large number of neurons $(H)$. $\mathrm{CB} 1 \mathrm{R}^{+}$terminals amply surround the somata of principal cells of both $\mathrm{CA}$ regions and dentate gyrus $\left(\mathrm{H}^{\top}\right)$. I,J, CRIP1a ${ }^{+}$profiles (arrowheads) are in intimate contact with CB1R+ terminals at the somatic surface of a neuron in CA1. K,L-L”, In the stratum radiatum, $\mathrm{CB} 1 \mathrm{R}^{+}$terminals repeatedly showed co-localization with $\mathrm{CRIP} 1 \mathrm{a}^{+}$profiles (arrowheads; open arrowhead points to a CB1 ${ }^{+} / \mathrm{CRIP1a}{ }^{-}$terminal. Bars: $1 \mathrm{~mm}\left(\mathrm{~A}^{\prime \prime}\right)$, $500 \mu \mathrm{m}\left(\mathrm{B}^{\prime \prime}\right), 200 \mu \mathrm{m}\left(\mathrm{H}^{\prime \prime}\right), 20 \mu \mathrm{m}(\mathrm{D}), 5 \mu \mathrm{m}(\mathrm{I}), 1 \mu \mathrm{m}(\mathrm{J}), 10 \mu \mathrm{m}(\mathrm{K}), 3 \mu \mathrm{m}(\mathrm{L})$.

Figure 2. CRIP1a in CA1 stratum radiatum is allocated to both excitatory and inhibitory presynaptic but not to postsynaptic domains. Images show immediate 
neighborhood with no demonstrable physical separation, i.e. direct contact, between CRIP1a ${ }^{+}$and $\mathrm{GAD}^{+}$or $\mathrm{VGLUT1}^{+}$profiles. In contrast, $\mathrm{DAGL \alpha}{ }^{+}$profiles remain clearly separated from CRIP1a ${ }^{+}$puncta. Bar: $3 \mu \mathrm{m} .{ }^{* *} \mathrm{p}<0.01$.

Figure 3. CRIP1a relocalization after CB1R activation. Image analysis and quantitative assessment of $\mathrm{CB} 1 \mathrm{R}^{+}$and CRIP1 $\mathrm{a}^{+}$profiles in mossy cell termini of the inner molecular layer of GABA-CB1R-KO mice after HU-210 application and compared to vehicle treatment. $\mathrm{HU}-210$ treatment did not change the proportion of overlapping $\mathrm{CB} 1 \mathrm{R}^{+} / \mathrm{CRIP} 1 \mathrm{a}^{+}$profiles. However, the proportion of contacting profiles significantly increased after CB1R activation, which was accompanied by a decrease of physically separated profiles without reaching statistical significance. For $X Z$ and YZ scale analysis, see orthogonal images. Arrowheads indicate overlaps. ${ }^{*} \mathrm{p}<0.05$. Bar: $2 \mu \mathrm{m}$.

Figure 4. CRIP1a attenuated CB1R internalization. HEK cells stably expressing HAtagged CB1R were transfected with GFP or CRIP1a and stimulated with HU-210 (100 nM) or vehicle. Top, CB1R internalization was assessed by immunoblot. HA immunoblot of HEK cell lysates following HU-210 or vehicle application and trypsin or versene treatment, as indicated by the table below. Bottom, CRIP1a expression decreased the amount of CB1R proteins being internalized after HU-210 stimulation (control, $27.94 \pm 1.75 \%$; CRIP1a, $19.38 \pm 2.92 \% ; p=0.031 ; N=6$ ). Data are expressed as means \pm SEM. ${ }^{*} p<0.05$.

Figure 5. AAV-mediated CRIP1a overexpression in the hippocampus. AAV-CRIP1a (A) or AAV-empty (B) was injected bilaterally into the hippocampus of wild-type C57BL/6N mice (AP: $-2.0, \mathrm{ML}: \pm 1.3$, DV: -1.6$)$. A, Immunohistochemical detection of 
the HA tag revealed robust transgene expression within the hippocampal formation in AAV-CRIP1a mice. B, HA-immunostaining showed the lack of transgene expression in AAV-empty controls. Bar in B: $250 \mu \mathrm{m}$. CAG, CMV immediate early enhancer/chicken $\beta$-actin hybrid promoter; WPRE, woodchuck hepatitis virus posttranscriptional regulatory element; $\mathrm{pA}$, bovine growth hormone polyadenylation sequence. C, Pyramidal neurons of CA1 expressed ectopic CRIP1a protein together with endogenous CB1R. Bar in $C^{\prime}: 50 \mu \mathrm{m}$. D, In AAV-CRIP1a animals, dentate gyrus granule cells were spared from AAV-mediated CRIP1a expression. E, Schematic diagrams of the mouse brain depict the approximate rostro-caudal extent of AAVmediated CRIP1a transgene expression (gray shading). Numbers indicate distance from bregma. F, Western blot analysis of hippocampal homogenates of AAV-empty $(\mathrm{N}=4)$ and AAV-CRIP1a $(\mathrm{N}=4)$ mice. Detection of ectopic CRIP1a protein using an antibody against the HA-tag showed CRIP1a bands exclusively in AAV-CRIP1a mice. Immunoblot using a CRIP1a antibody revealed both endogenous and ectopic CRIP1a protein in AAV-CRIP1a mice. Only endogenous CRIP1a protein was detected in AAV-empty animals. Cell adhesion molecule F3 or actin was used as loading control. G, CRIP1a levels were significantly elevated in AAV-CRIP1a mice as compared to AAV-empty controls. CB1R levels were unaltered. Data were normalized to the loading control F3. H, Stimulation of $\left[{ }^{35}\right.$ S]GTPYS binding in hippocampal homogenates of AAV-empty $(N=7)$ and AAV-CRIP1a mice $(N=8)$ was determined with various concentrations of the CB1R agonist HU-210. Basal binding was measured in absence of $\mathrm{HU}-210$ and defined as $0 \%$ in each experiment. Data are presented as percentage stimulation above basal $\left[{ }^{35} \mathrm{~S}\right] \mathrm{GTPYS}$ binding. The nonlinear regression curve illustrates that CRIP1a overexpression resulted in significantly enhanced cannabinoid-induced G protein activation. Data are expressed as means \pm SEM. ${ }^{* *} p<0.01,{ }^{* *} p<0.001$. 
Figure 6. Functional consequences of CRIP1a overexpression on hippocampal CA1 pyramidal neurons. A, Amplitude of eEPSCs from recordings in AAV-empty (open circles) and AAV-CRIP1a mice (black circles). The $10 \mathrm{~s}$ depolarization step is indicated by an arrow. B, Top, averaged eEPSCs immediately before $(1 ; \mathrm{n}=5$ traces) and after $(2 ; n=3$ traces $)$ the $10 \mathrm{~s}$ depolarization step, recorded in AAVempty (left) and AAV-CRIP1a (right) mice. Bottom, summary bar graph showing the magnitude of DSE after $5 \mathrm{~s}$ (hatched bars) and $10 \mathrm{~s}$ (solid bars) depolarization. Note that DSE did not differ between the two groups. C, Averaged eEPSCs after bath application of the CB1R agonist HU-210 $(1 \mu \mathrm{M})$. D, Summary bar graph showing the magnitude of eEPSC depression by HU-210. CRIP1a overexpression enhanced the depression of eEPSCs $60 \mathrm{~min}$ after HU-210 application. Data are expressed as means \pm SEM. ${ }^{*} p<0.05$.

Figure 7. CRIP1a and kainic acid-induced seizures. Seizures were induced in AAVCRIP1a mice $(N=23)$ and AAV-empty controls $(N=23)$ by injection of kainic acid (30 mg/kg, i.p.). A, Seizure severity was reduced in AAV-CRIP1a mice as compared to AAV-empty controls. B, There was no difference in the latency to reach seizure score 3. C, The maximum seizure severity was significantly lower in AAV-CRIP1a mice than in AAV-empty animals. D, Kaplan-Meier survival curves depict a higher survival rate of AAV-CRIP1a mice compared to AAV-empty controls during KA treatment, which was close to but did not reach statistical significance. Data are expressed as means \pm SEM. ${ }^{*} p<0.05$. 
Click here to download high resolution image

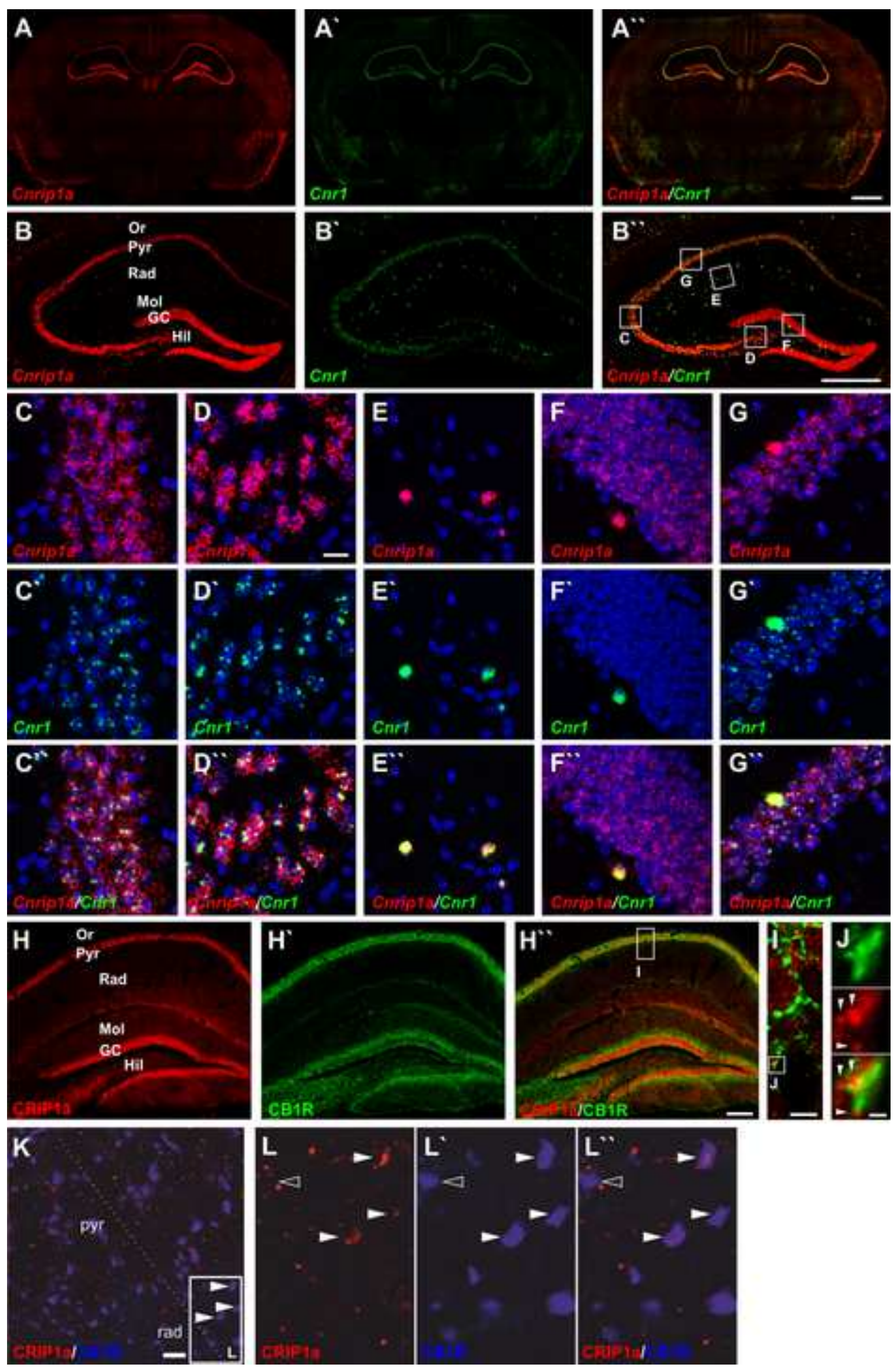





GAD VGIuT1 

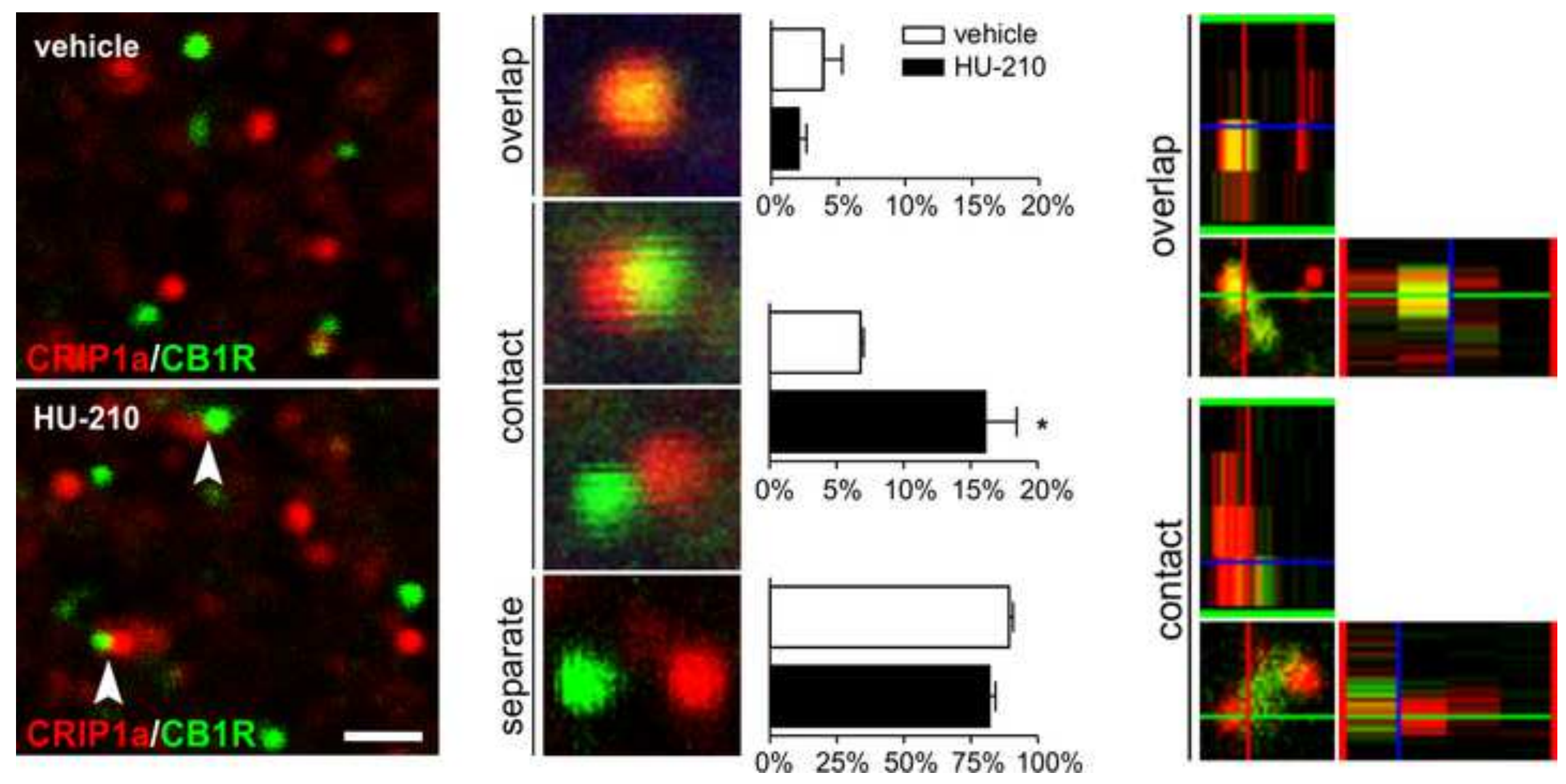


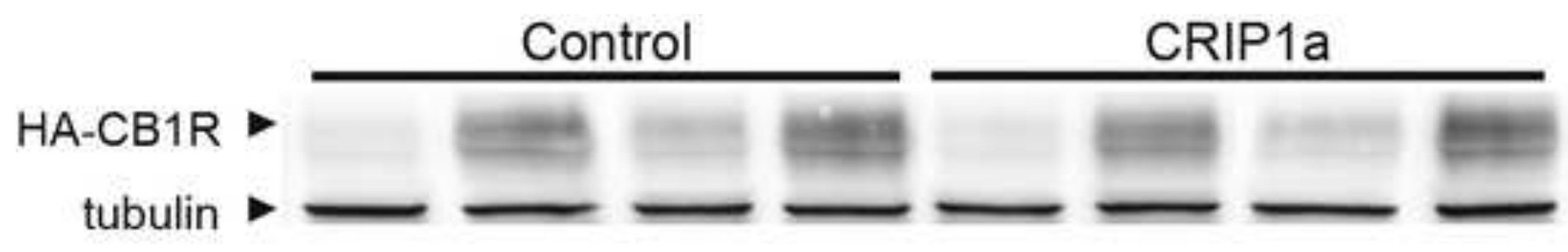

\begin{tabular}{c|c|c|c|c|c|c|c|c} 
vehicle & + & + & - & - & + & + & - & - \\
\hline $\mathrm{HU}-210$ & - & - & + & + & - & - & + & + \\
\hline Trypsin & + & - & + & - & + & - & + & - \\
\hline Versene & - & + & - & + & - & + & - & +
\end{tabular}

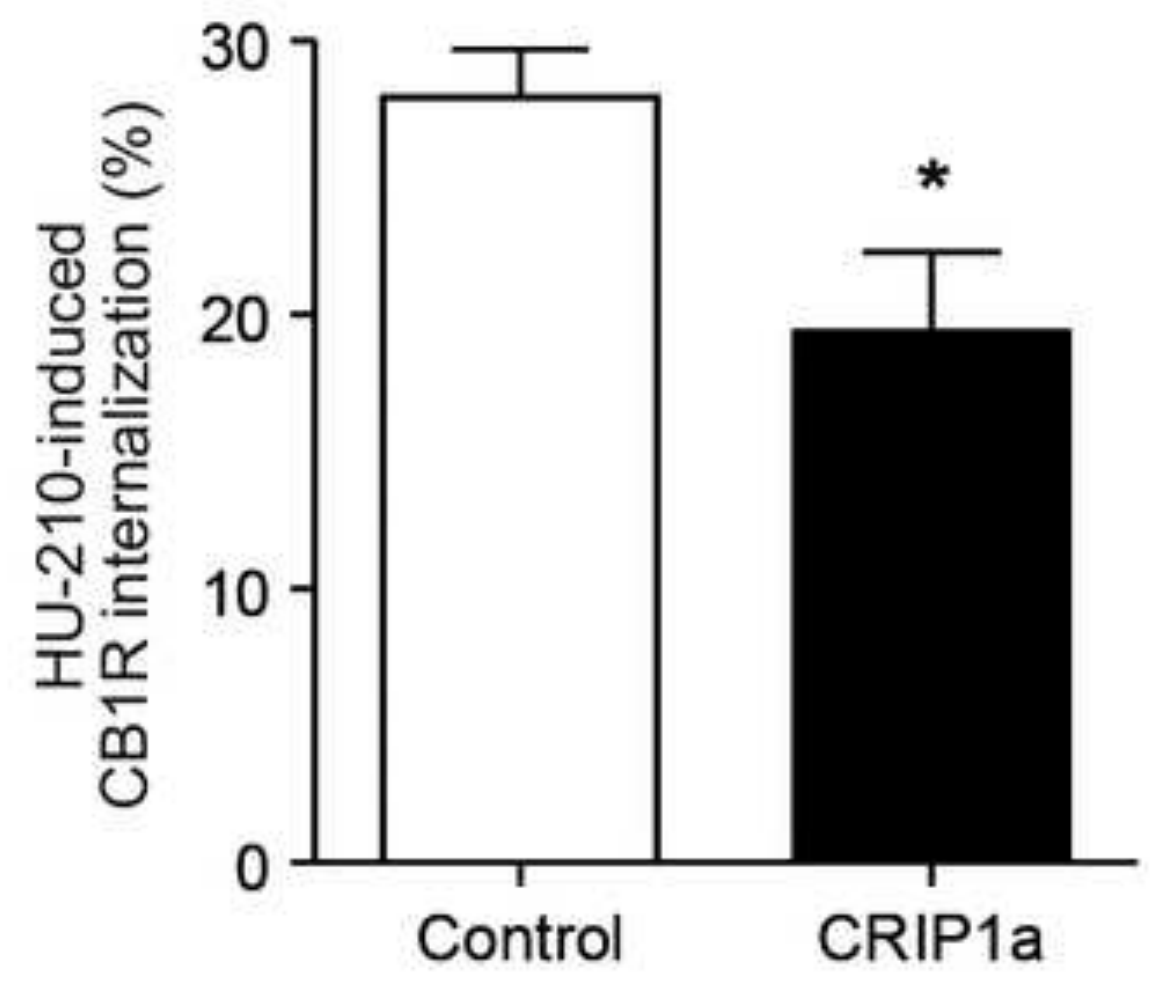



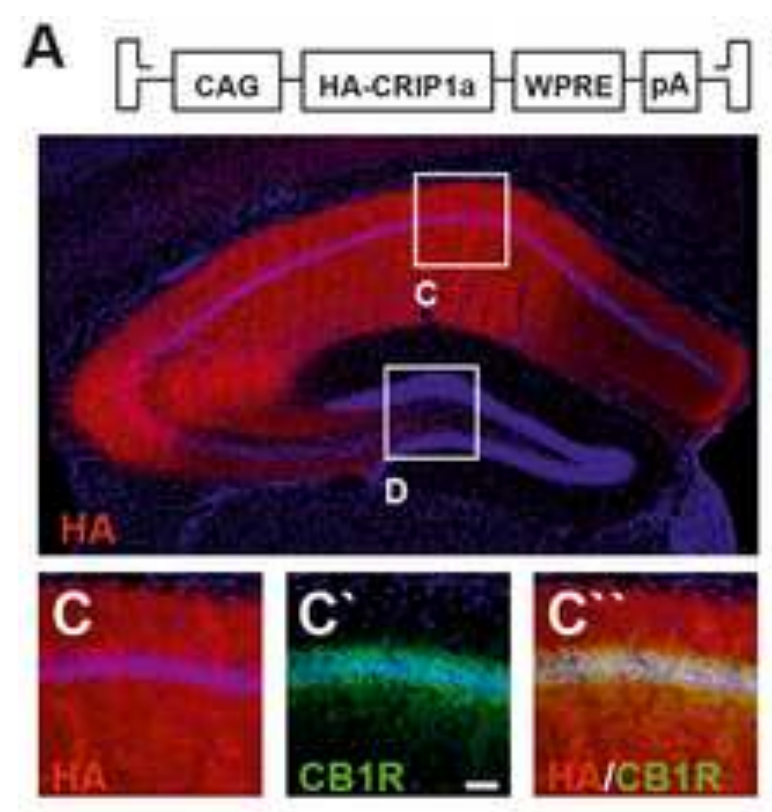

F



\section{B}

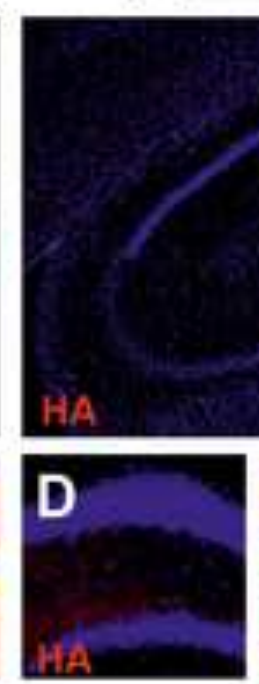

G


E

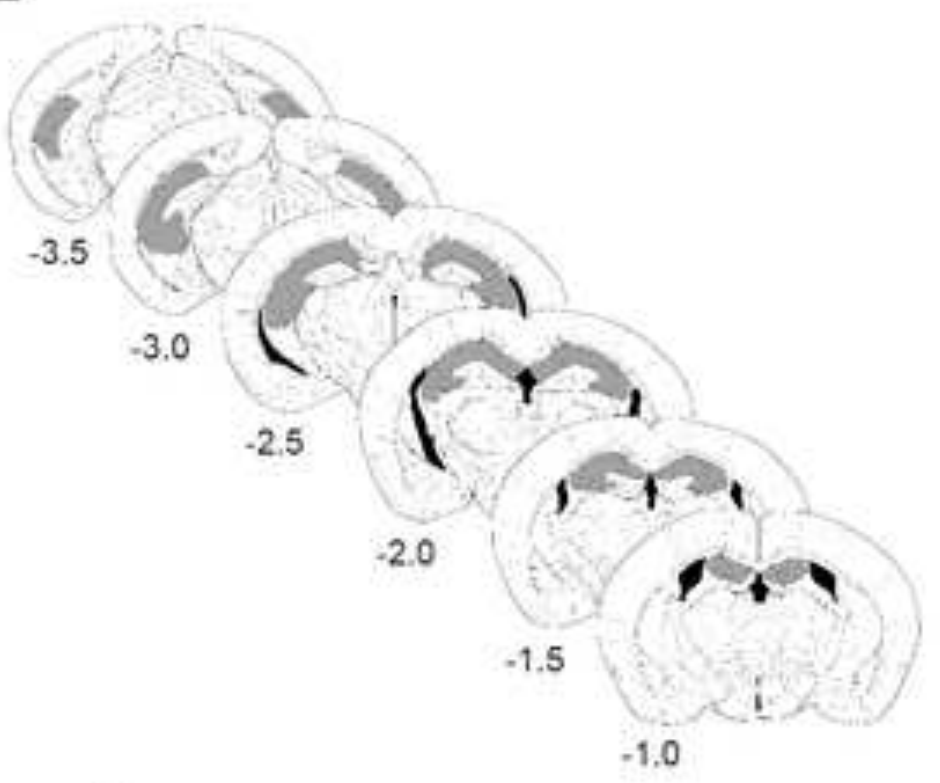

H

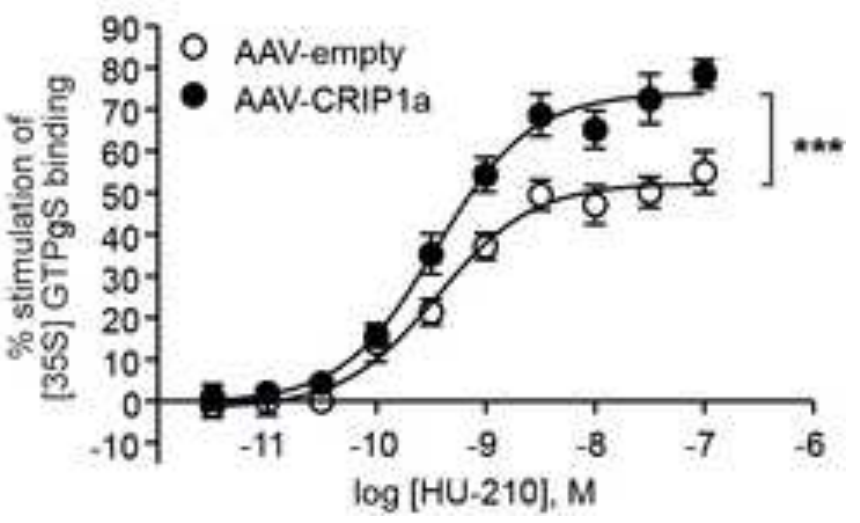




A

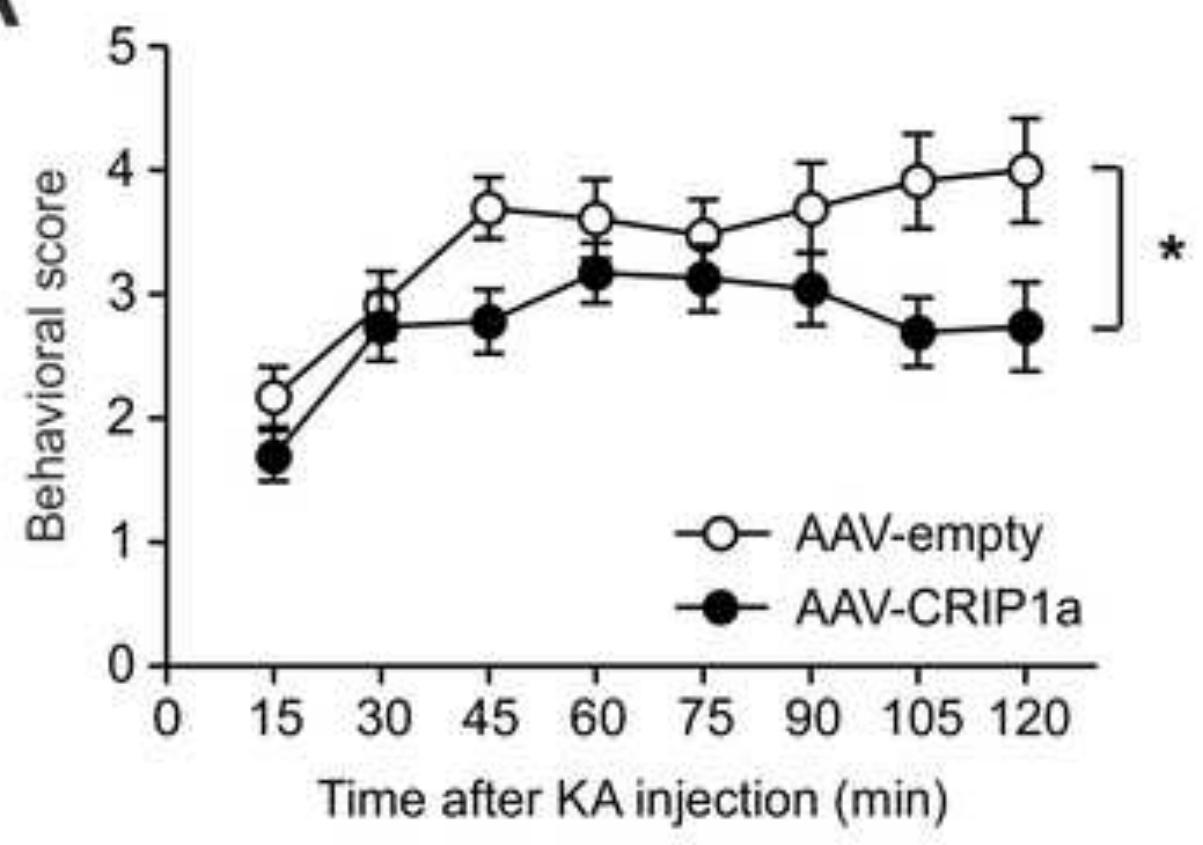

B

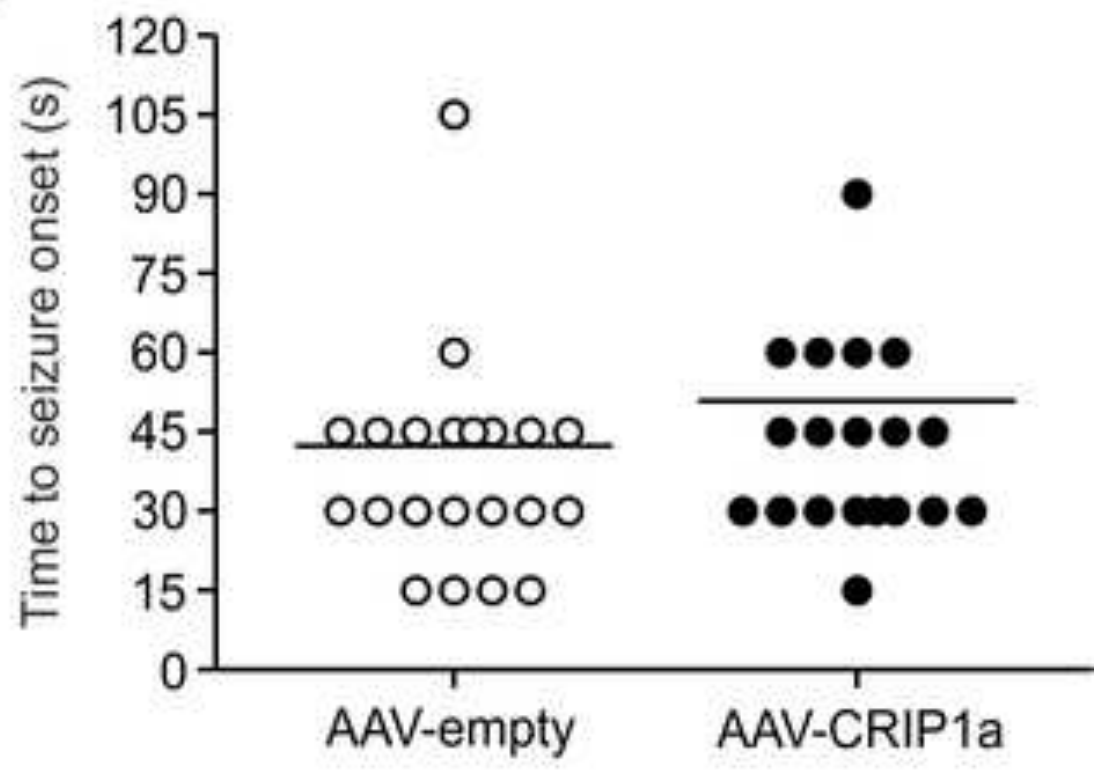

D
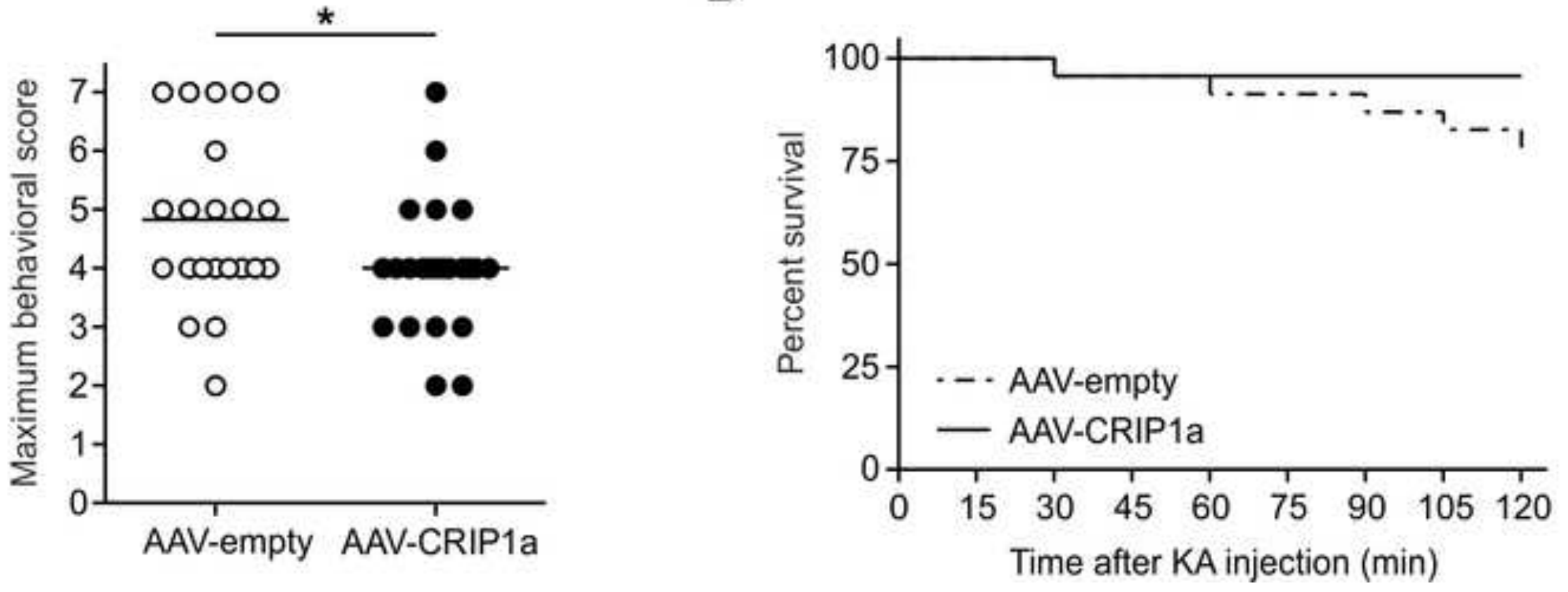


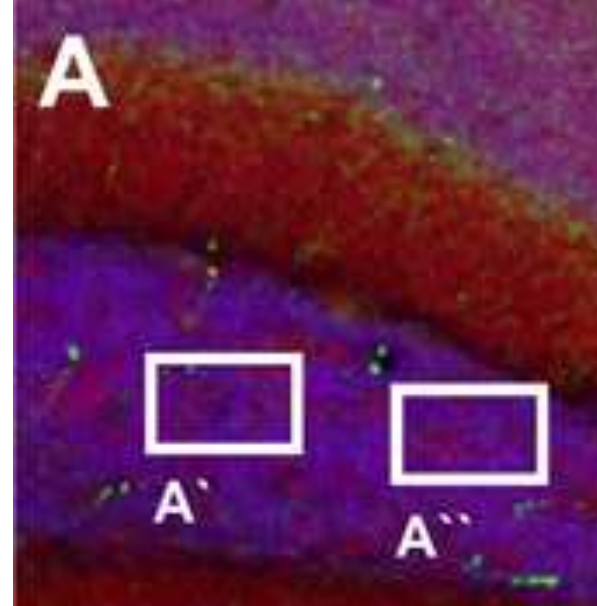

B



B'
C

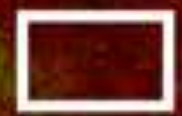

$C^{*}$

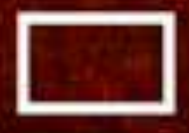

C

GAD/ Gale / VGlutr -

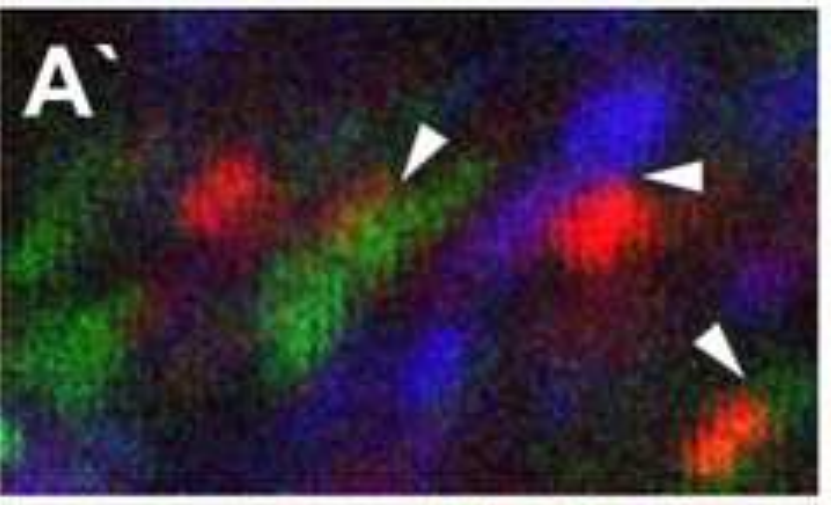

$A^{*}$

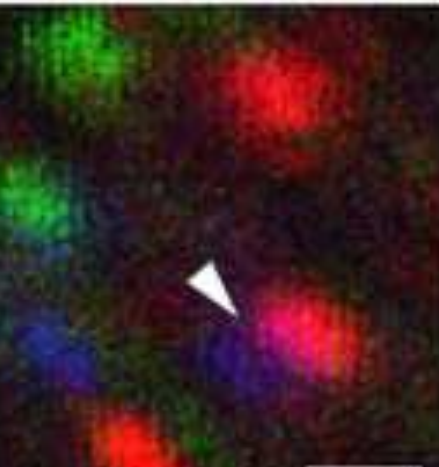

B

$C^{\prime \prime 2}$

VGIUT3/CRIP1a:

C C

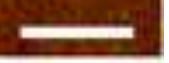

$\mathbf{B}^{\circ}$

4
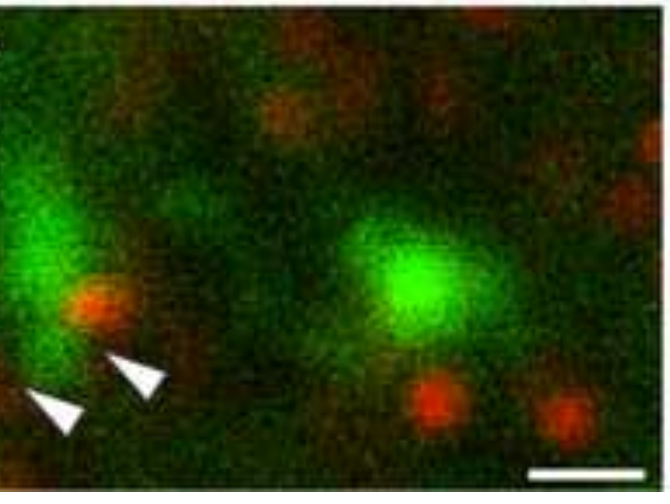

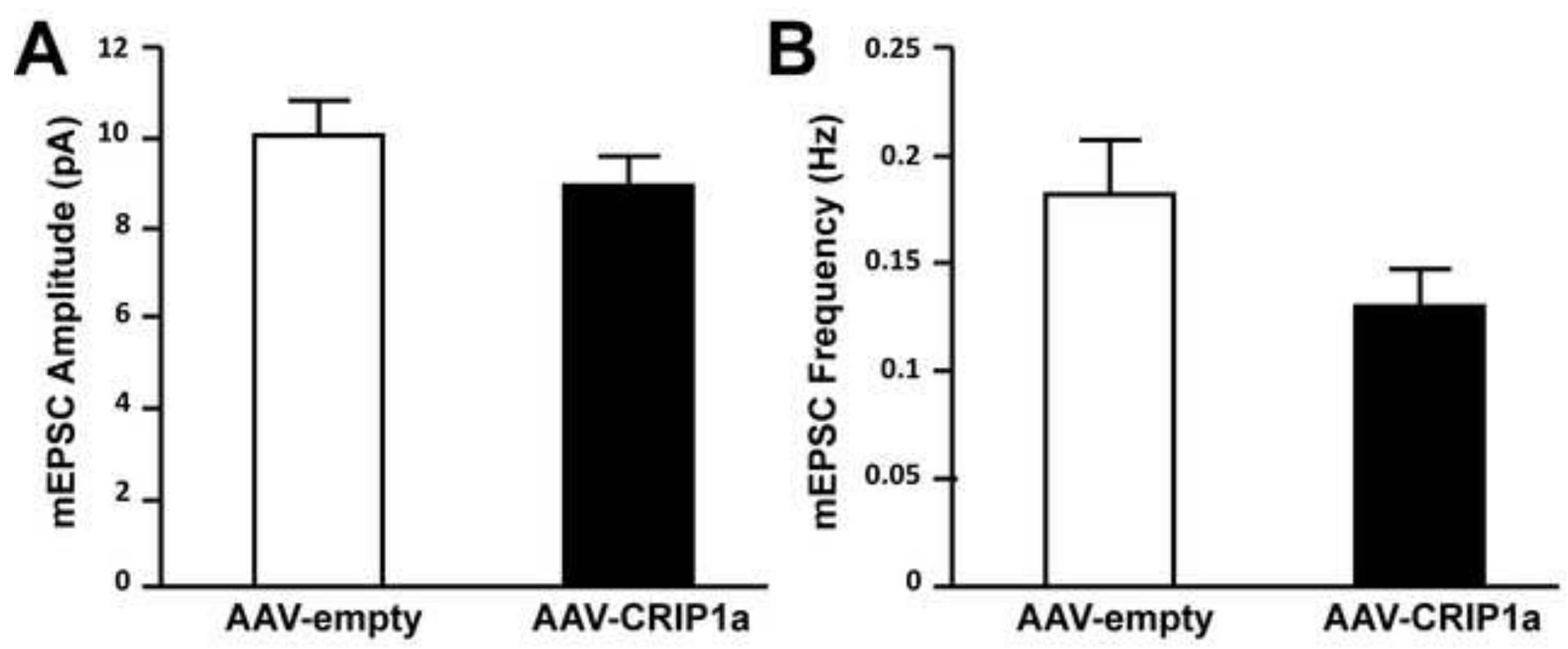

C aAV-empty



D

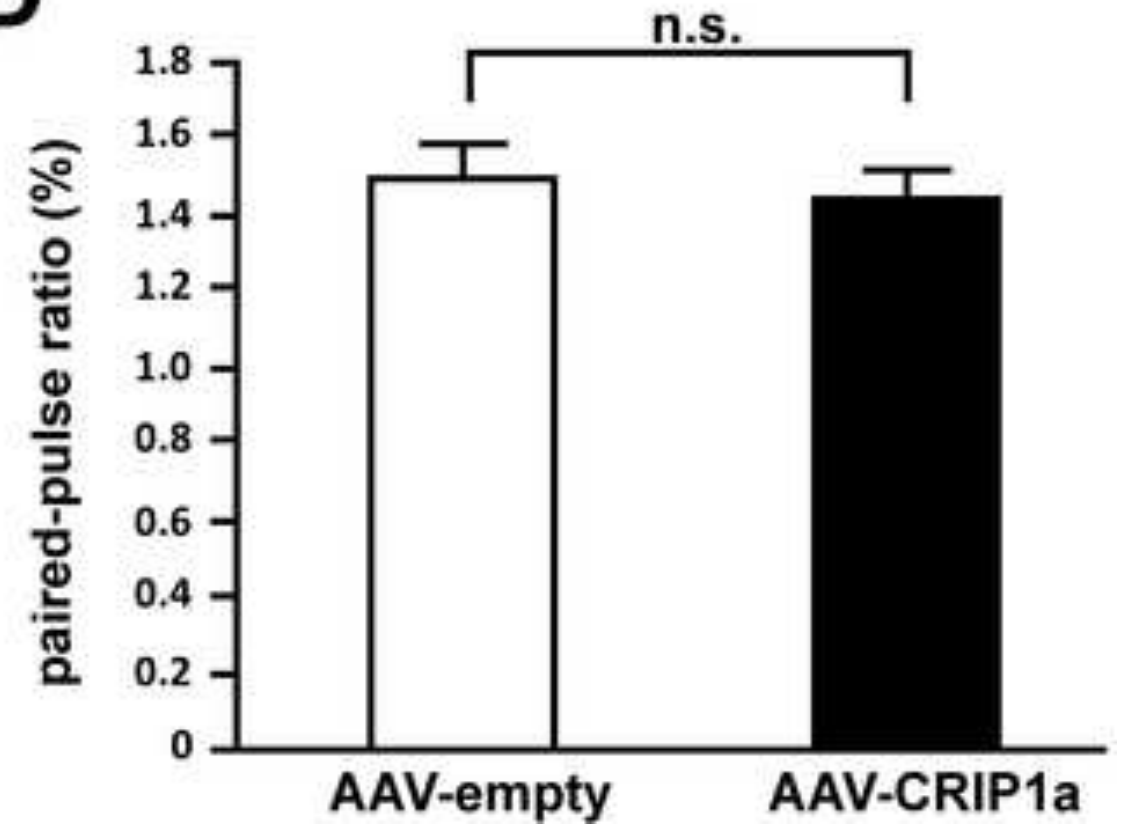



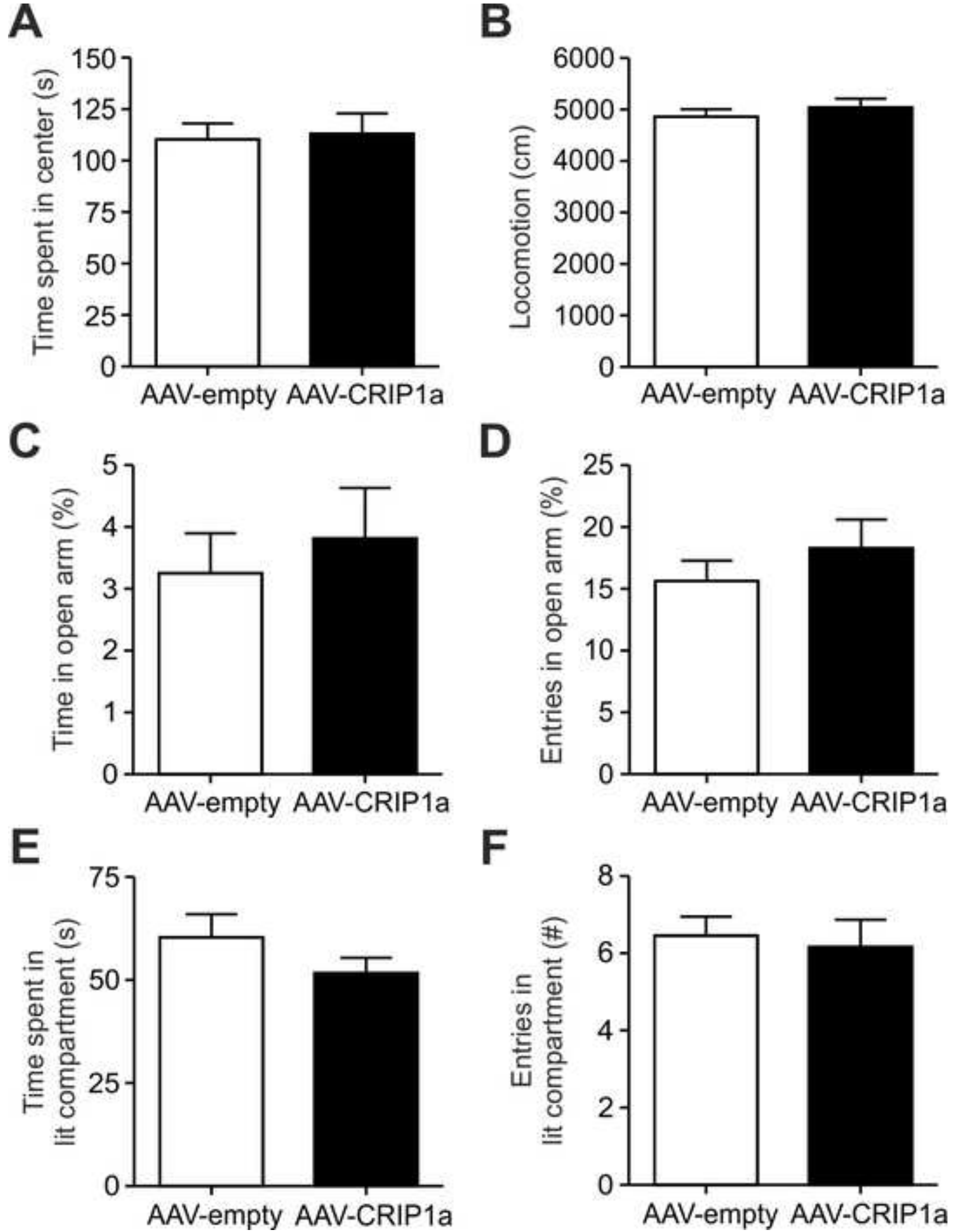

$\mathbf{F}$

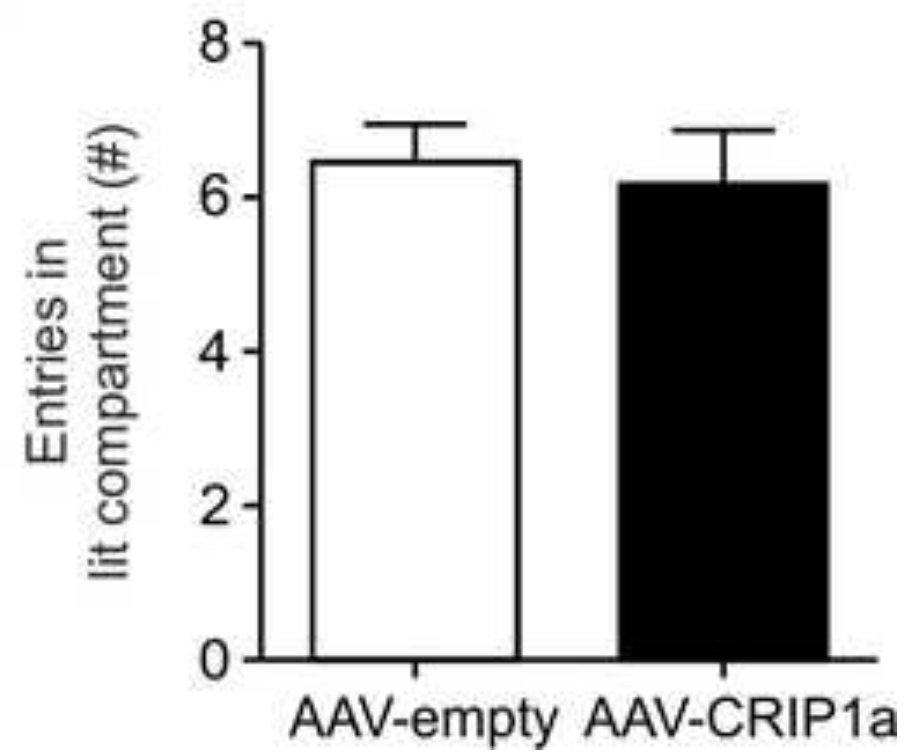




\section{Supplementary Material}

\section{Brain Structure \& Function}

\section{Cannabinoid receptor interacting protein Crip1a modulates CB1 receptor signaling in mouse hippocampus}

Stephan Guggenhuber ${ }^{1}$, Alan Alpar ${ }^{2,3,4}$, Rongqing Chen ${ }^{5}$, Nina Schmitz ${ }^{1}$, Melanie Wickert ${ }^{1}$, Tobias Mattheus ${ }^{1}$, Anne E. Harasta ${ }^{1,6}$, Martin Purrio ${ }^{1}$, Nadine Kaiser ${ }^{1}$, Maurice R. Elphick ${ }^{7}$, Krisztina Monory ${ }^{1}$, Werner Kilb ${ }^{5}$, Heiko J. Luhmann ${ }^{5}$, Tibor Harkany ${ }^{2,8}$, Beat Lutz ${ }^{1, *}$, Matthias Klugmann ${ }^{1,6, *}$

${ }^{1}$ Institute of Physiological Chemistry, University Medical Center of the Johannes Gutenberg University, D-55128 Mainz, Germany. ${ }^{2}$ Division of Molecular Neurobiology, Department of Medical Biochemistry and Biophysics, Scheeles väg 1:A1, Karolinska Institutet, SE-17177 Stockholm, Sweden. ${ }^{3}$ Research Group of Experimental Neuroanatomy and Developmental Biology, Hungarian Academy of Sciences, Budapest, Hungary. ${ }^{4}$ Department of Anatomy, Histology and Embryology, Semmelweis University, Budapest, Hungary. ${ }^{5}$ Institute of Physiology, University Medical Center of the Johannes Gutenberg University, D-55128 Mainz, Germany. ${ }^{6}$ Department of Physiology \& Translational Neuroscience Facility, School of Medical Sciences, UNSW, High Street, Randwick, NSW 2052, Sydney, Australia. ${ }^{7}$ School of Biological \& Chemical Sciences, Queen Mary University of London, London E1 4NS, UK. ${ }^{8}$ Department of Molecular Neuroscience, Center for Brain Research, Medical University of Vienna, Spitalgasse 4, A-1090 Vienna, Austria.

Correspondence should be addressed to Matthias Klugmann or Beat Lutz. Email:m.klugmann@unsw.edu.au or blutz@uni-mainz.de. 


\section{Materials and Methods}

\section{Behavioral testing}

Behavioral testing commenced at four weeks after vector injections, when AAV-mediated transgene expression has reached maximum and stable levels. AAV-CRIP1a and AAV-empty animals $(n=21-25)$ were subjected to the tests in the order listed below. Animals were left undisturbed for at least 5 days between the different test sessions. The experimenter was blind to the treatment of the animals. Locomotor activity and anxiety-related behavior was tested using an open field box and the light/dark emergence test, respectively, as described (Schneider et al. 2007). Inherent anxiety was investigated using the elevated plus maze, consisting of two open arms $(35 \mathrm{~cm}$ length, $6 \mathrm{~cm}$ width) and two enclosed black arms (35 cm length, $6 \mathrm{~cm}$ width, $20 \mathrm{~cm}$ height) at $1 \mathrm{~m}$ above the floor. The light on the floor of the open arms and the center had about 30 lux. At the beginning of the test, the mouse was placed in a close arm, and the behavior was video-monitored for $5 \mathrm{~min}$. Recordings were used to determine the time spent in the different arms, the entire entries to the arms as well as head dips and risk assessment.

\section{References}

Schneider M, Spanagel R, Zhang SJ, Bading H, Klugmann M (2007) Adenoassociated virus (AAV)-mediated suppression of Ca2+/calmodulin kinase IV activity in the nucleus accumbens modulates emotional behaviour in mice. BMC neuroscience 8:105. doi:10.1186/1471-22028-105 


\section{Legends to Supplementary figures}

Figure 1. Immunodetection of CRIP1a in the hilus of mouse hippocampus. AA“, B-B" ${ }^{\prime \prime}$ CRIP1a expression sites are in direct contact with $\mathrm{GAD}^{+}$, VGLUT $^{+}$or VGLUT3 ${ }^{+}$terminals (arrowheads). C-C"', CRIP1a and DAGLa expression sites did not overlap but were generally in close contact. Bars: 100 $\mu \mathrm{m}(\mathrm{A}, \mathrm{B}, \mathrm{C}), 2 \mu \mathrm{m}\left(\mathrm{A}^{\prime \prime}, \mathrm{B}^{\prime}, \mathrm{C}^{\prime \prime}\right)$.

Figure 2. CRIP1a does not affect excitatory synaptic transmission. A, B, Amplitude and frequency of miniature EPSCs were not significantly different in CA1 pyramidal cells from AAV-empty and AAV-CRIP1a transfected animals. C, Typical current traces illustrating paired-pulse facilitation of the $2^{\text {nd }}$ eEPSC. Note comparable paired-pulse facilitation between AAV-empty and AAVCRIP1a mice. D, Bar graph illustrating paired-pulse ratio of evoked EPSCs in AAV-empty and AAV-CRIP1a mice. n.s., non significant.

Figure 3. CRIP1a overexpression did not affect locomotion and anxiety behavior. A, B, Animals were subjected to an open field test. The time spent in the center $(p=0.83)$ and the distance travelled $(p=0.42)$ did not differ between AAV-empty and AAV-CRIP1a mice. C, D, In the elevated plus maze, there was no significant difference in the time spent in the open arm $(p=0.59)$ or in the entries into the open arm $(p=0.36)$ between the two groups. $\mathbf{E}, \mathbf{F}$, The light/dark test revealed that AAV-empty and AAV-CRIP1a animals did not differ in the time spent in the lit compartment $(p=0.22)$ and in the entries into the lit compartment $(p=0.73) . N=21$ to 25 mice per group. Data are expressed as means \pm SEM. 